\title{
ENVIRONMENTAL CONCERN LEADS TO TRADE SKEPTICISM ON THE POLITICAL LEFT AND RIGHT*
}

\author{
Lukas Rudolph ${ }^{\dagger}$ Franziska Quoß ${ }^{\ddagger}$ Romain Buchs ${ }^{\S}$ \\ Thomas Bernauer $\mathbb{1}$
}

\begin{abstract}
The environmental implications of international trade appear to be associated with public backlash against trade liberalization and efforts at greening international trade. Because public support is essential to environmental and trade policy-making alike, we examine the trade-environment nexus from a public opinion perspective. We investigate whether negative attitudes towards trade are in fact fueled by concern over its environmental consequences. We argue that environmental concern affects how citizens evaluate the costs and benefits of trade, and that such evaluation is moderated by political ideology. The empirical analysis relies on a population-based survey experiment and a large representative survey in Switzerland, a small open economy. We show that environmental concern leads to decreasing appreciation of and support for international trade, with different manifestations of trade skepticism on the political left and right. Relating to the debate over global environmental footprints of domestic consumption, we do not find that citizens care more about environmental damage at home than abroad. This suggests (i) that policy-makers should focus more on greening global supply chains, and thus trade, if they wish to sustain public support for liberal international trade policy, and (ii) that the public follows informational cues on the environmental impacts of trade.
\end{abstract}

Wordcount: 8443

Keywords: environmental concern, trade preferences, public opinion, experiment, survey

*Authors' note: The data collection for the two surveys was funded by the Swiss Federal Office for the Environment, and by ETH Zurich.

${ }^{\dagger}$ LMU Munich and ETH Zurich, lukas.rudolph@gsi.uni-muenchen.de

${ }_{\ddagger}^{\ddagger}$ ETH Zurich, franziska.quoss@ir.gess.ethz.ch

ミETH Zurich, romain.buchs@alumni.ethz.ch

IETH Zurich, thbe0520@ethz.ch 


\section{Introduction}

International trade increases the efficiency of production and the number of goods and services available to consumers globally (Ben-David and Loewy 1998). At the same time, trade also results in negative externalities (Hertwich and Peters 2009). This raises the question of whether the geographical dissociation of production and consumption trough trade leads to shifts in environmental impacts among consuming and producing economies (Wood et al. 2018). In public debates on the trade-environment nexus, transnational business activities are commonly associated with environmental problems worldwide (Copeland and Taylor 2003; Spilker, Koubi and Bernauer 2017). While a decoupling of economic growth from resource use is necessary to reduce the global environmental footprint of humanity to sustainable levels (Hoekstra and Wiedmann 2014), such decoupling thus far appears to take place primarily in high-income countries, but only if footprint shifting via trade is not factored in (Wiedmann and Lenzen 2018). Such footprint shifting, i.e., pollution-intensive production moving from higher- to lower-income countries, has been noted in many contexts (e.g., Kanemoto et al. 2014). In fact, negative environmental impacts of global production networks appear to accrue over-proportionally in poorer countries (see Yang et al. 2012; Aklin 2016; Jorgenson and Rice 2005).

At the same time, we note that many citizens in richer countries, both from the left and right of the political spectrum, are skeptical about international trade liberalization. ${ }^{1}$ Prominent examples are the failed negotiations between the European Union (EU) and the United States on the Transatlantic Trade and Investment Partnership (TTIP) and between the EU and Canada on the Comprehensive Economic and Trade Agreement

$1 \quad$ The 2019 Eurobarometer survey found that $80 \%$ of respondents agree that rules for international trade are necessary, $60 \%$ agree that EU trade policy should take social/environmental impacts of trade into account, and $50 \%$ name respect for EU environmental/health standards as a main priority of EU trade policy (up 20 percentage points compared to 2010 and top-named priority in seven EU countries; Eurobarometer 2019). 
(CETA). These are high-profile cases where the stalling of trade negotiations has been linked to the opposition of the public, with motivations voiced prominently, including environmental concern (Eliasson and Huet 2018; Hübner, Deman and Balik 2017). This points to the crucial role public opinion plays for whether and how trade policy is enacted. ${ }^{2}$ Hence a better understanding of citizens' preference formation in this area is important (Dür and Mateo 2014; Kono 2008). We therefore address two core questions in this article: Does environmental concern more generally and concern about the environmental impacts of trade in particular explain trade skepticism? Does political ideology moderate this proposed relationship?

Theoretically, the existing literature on trade preferences focuses to a large extent on the embedded liberalism argument. This argument explains trade liberalization and globalization backlash based on economic issues, particularly redistribution through trade (Kaltenthaler, Gelleny and Ceccoli 2004; Burgoon 2009; Rodrik 2018; Bearce and Moya 2020; Maria Schaffer and Spilker 2019; Scheve and Slaughter 2001; Rho and Tomz 2017). In this argument, non-trade factors (e.g., environmental concern) are subordinate to economic considerations or constitute economic protectionism in disguise (Morin, Dür and Lechner 2018). However, recent studies show that non-economic considerations play an important role for trade preference formation (see, Mansfield, Milner and Rudra 2021; Walter 2021, for an overview) and a small recent literature examines the effect of environmental considerations on trade preferences in particular. This largely observational

$2 \quad$ Public opinion had little place in early theories of foreign policymaking, as the public was proposed to know little on and matter little for foreign policy-making (see, Milner and Tingley 2013, for an overview on the arguments). Recent research points to the public both being a vigilant observer (e.g., Kertzer and Zeitzoff 2017) and its preferences mattering for foreign policy-making (Goldsmith and Horiuchi 2012), including trade policy (see, e.g., Dür and Mateo 2014, and the examples indicated above). Concerning environmental policy, as summarized by Nguyen, Huber and Bernauer (2021), studies both in the US and Europe indicate that political elites follow the environmental preferences of their constituents in environmental policy-making (e.g., Vandeweerdt, Kerremans and Cohn 2016; Anderson, Böhmelt and Ward 2017; Weaver 2008). 
literature shows that in developed (Bechtel, Bernauer and Meyer 2012; Ehrlich 2010) and developing countries (Spilker, Bernauer and Umaña 2018; Nguyen and Bernauer 2015), many citizens are worried about the environmental impacts of trade. Directly related to our case, Bechtel, Bernauer and Meyer (2012) show that Swiss citizens concerned about the environment are more skeptical regarding economic globalization and more supportive of protectionist trade policy. Building on these contributions, we propose that higher environmental concern should be linked to lower preferences for free trade. In line with Bechtel, Bernauer and Meyer (2012), we also investigate whether environmental concern has an influence on trade policy preferences irrespective of political ideology, or whether and how the effect of environmental concern on trade preferences differs on the political left and right. To date, it is still unclear whether the relationship between environmental concern and trade preferences is causal. Also, political ideology might be a confounder in the relationship between environmental concern and trade preferences, but could also be a moderator. As noted by Ehrlich (2018), political ideology is regularly found to be a strong predictor of both protectionism and free trade, and matters for trade preferences on the level of states (Dutt and Mitra 2005), legislators (Milner and Tingley 2011) and citizens (Jedinger and Burger 2020). At the same time, a large literature on environmental attitudes and environmental policy preferences pays significant attention to effects of general political attitudes (e.g., Czarnek, Kossowska and Szwed 2021; Dunlap 1975). Hence, we investigate why environmental concern and trade policy preferences co-occur. Even if environmental concern was related to trade policy preferences, this effect could mainly run through correlation with political ideology, or go beyond that and moderate the effect of environmental concern on trade.

We investigate this relationship in the context of Switzerland. Trade openness is vital to Switzerland's economic model. Switzerland has a higher trade volume and global- 
ization index than its neighboring countries and the US (see Appendix Section A.4.3). Consequently, a substantial share of voters (9\%) sees trade policy as a top-3 policy issue for Switzerland (while even more, 36\%, indicate this is the case for the environment). Moreover, trade and environmental policy meaningfully differentiate political parties and candidates in Switzerland, who show large variation in the policies they offer to voters. However, Swiss citizens still hold levels of environmental concern comparable to citizens of other OECD countries and hold a similar level of perception of personal trade impact, trade knowledge and preferences on limiting international trade compared to citizens in other high-income countries (see Appendix Section A.4 for details). Additionally, in the consociational political system of Switzerland, with its heavy reliance on formal and informal coalitions (see e.g. Hänggli and Häusermann 2015), citizens rely on political ideology to structure policy preferences (cf. Fortunato, Stevenson and Vonnahme 2016, who propose that ideology matters for particular institutional contexts only; see Appendix Section A.3 for details). Altogether, this suggests that Switzerland is a case well-suited for our question as environmental concern and trade policy both matter for the citizenry, citizens face a meaningful trade-off, and political ideology is potentially a relevant moderator for Swiss citizens' political attitudes.

The research reported in this paper contributes to the literature in three ways. First, we study the relationship between environmental concern and trade skepticism with new data from a large and high-quality population-representative sample of the Swiss population $(N=4800)$. This data allows us to employ very nuanced measures of both environmental attitudes and trade preferences in the analysis. Thereby, we shed more light on whether and how environmental concern relates to differing degrees and types of trade skepticism. Second, we take the current literature an important step forward by investigating whether an experimental manipulation of the environmental impacts of 
trade in both a positive and negative direction (which is paramount to simulating different elite cues), via a survey-embedded vignette experiment $(N=1538)$, induces shifts in trade preferences. Third, we investigate whether and how political ideology moderates how environmental concern relates to trade preferences in the correlational and surveyexperimental setting. Taken together, we fill an important gap in our understanding of how citizens' environmental attitudes inform trade preferences, and how political ideology might moderate this relationship.

Empirically, we show that ideology indeed affects the relationship between environmental concern and trade attitudes, and that environmental concern leads to different types of trade skepticism on the political left and right. Such insights are important for better understanding the potential for pro- and anti-free-trade coalitions along and across conventional ideological lines in modern democracies (Milner and Judkins 2004). Our study also provides insights into whether the relation between non-economic attitudes, such as environmental concern, and preferences on limiting free trade is causal in nature, or whether this relationship reflects economic protectionism in disguise (Ehrlich 2010). We experimentally manipulate respondents' understanding of the impact of trade on the environment, both in their home country and abroad, and investigate both positive and negative shifts in respondents' environmental concern. This allows us to causally link specific concern or serenity (i.e., decreased concern) for trade impacts to shifts in how respondents assess the benefits from trade as well as their trade policy preferences. Our correlational evidence reveals a nuanced relationship between different dimensions of trade and environmental attitudes. We find robust evidence that individuals with higher levels of environmental concern are more trade skeptic. However, while environmental concern correlates with negative attitudes towards economic globalization generally on the political left, it correlates with protectionist trade policies on the political right. As we control 
for ideology (next to several other socio-demographic factors), we are confident that this environment-trade skepticism is more than "protectionism in disguise". In a second step, we experimentally increase or decrease concern over the environmental impacts of trade via visual and textual survey-experimental vignettes. With the concern-inducing vignette, an increase in concern relates causally to a perception of lower benefits from international trade, more negative feelings towards international trade, and in tendency more protectionist trade policy attitudes (and vice versa). We observe this relation for both the political left and right. We thereby provide causal evidence that attitudes towards trade are a function of environmental preferences and beliefs. Lastly, we find that respondents do not differentiate between trade harming the domestic or foreign environment when forming trade preferences.

At a more general level, our research adds to previous work that highlights the role of information (Rho and Tomz 2017; Hainmueller and Hiscox 2006) and non-economic drivers (Mansfield and Mutz 2009) in trade policy preference formation. Sabet (2016), e.g., argues that non-material predispositions (in her case sentiment toward foreign cultural influences) is a first-order determinant of trade preferences, and economic considerations only come to play a role for trade preference formation when these sentiments are weak. Finally, and given that both our sample and the broader European public (Eurobarometer 2019) is rather concerned about the environmental impacts of trade, our findings are in line with recent arguments that irrespective of political ideology individuals are likely to support a "greening" of international trade, and that environmental clauses in trade agreements could help alleviate public concerns over free-trade agreements and environmental footprint shifting (Jinnah and Morin 2020). 


\section{Methods}

\subsection{Population-representative survey}

We rely on two complementary data sources to assess whether environmental concern leads to more negative attitudes towards international trade and whether this relationship is affected by political ideology.

Our first set of data comes from the Swiss Environmental Panel (SEP), a large dualmode panel survey by the authors, carried out since spring 2018. The sampling is conducted by the Swiss Federal Statistical Office (BfS), resulting in a sample that is representative of the Swiss resident population aged $15+$. The items on environmental and trade attitudes are part of the first wave of the panel, fielded between February and May 2018. The sample size of the first wave is 4,813 , resulting in a raw response rate of $32.17 \% .^{3}$

The dependent variables in our model are based on a battery of six questions measuring different facets of trade policy preferences on a 5-point Likert scale (see Appendix Table A.3 for detailed wording). The first item, 'economic openness', measures attitudes toward international market openness in general, while the second, "economic openness for companies', focuses on the impacts of globalization on companies. The third and fourth items address sector-specific protectionist measures: 'job-related protection' covers the attitude of respondents regarding trade restrictions to protect jobs in sectors where they are at risk, while 'agriculture protection' asks respondents whether the agricultural sector should be protected from imports. Items five and six address economic liberalism from two different angles: 'price and quality' asks respondents whether the origin of a product should matter beyond price and quality, whereas 'safe food access' asks whether the imports of food deemed safe for health should be restricted.

3 Further information on the panel and access to data is available at https://ib.ethz.ch/research/ sep.html. 
Items one, three, and five are identical to items used in Bechtel, Bernauer and Meyer (2012). For the presentation of results, we inverted the scale of some items such that higher values always indicate more negative attitudes towards trade (trade skepticism). The six items describing trade attitudes are aggregated into a single variable ("main dimension of trade') through a Principal Component Analysis (PCA) that explicitly takes into account and imputes missing values.

Concern for the environment is measured through a battery of nine items with a 5point Likert scale (see Appendix Table A.4 for detailed wording). Those nine items span the three components of environmental concern commonly identified in the sociological literature (see, e.g., Franzen and Meyer 2009): the cognitive component (the understanding of environmental issues and risks), the affective component (the emotional reaction to those issues and risks), and the conative component (the willingness to address those issues and risks). The nine items describing environmental concern are aggregated into a single dimension ('main dimension of environmental concern') through a PCA, which is validated with a scree test. Political ideology is measured on a left-right scale, which ranges from 0 (left) to 4 (right), with each of the response options explicity labeled, namely "left", "center-left", "center", "center-right" and "right". 4

\subsection{Survey experiment}

Our second set of data comes from a survey experiment which was fielded by IPSOS via computer-assisted web interviews with 1538 respondents from Switzerland. We used quotas on age, gender, region, and education to ensure that survey participants are com-

$4 \quad$ We apply established survey items for left-right self-placement to capture ideology. While ideology is challenging to measure (Bauer et al. 2017), we show empirically that left-right placement predicts partisanship, is stable over time, and similarly applied in the three Swiss language regions (based on the Swiss Environmental Panel data). Also, we show that the left-right self-placement is unaffected by the experimental treatments as a precondition to meaningfully interpret moderation effects. See Appendix Section A.3 for details. 
parable to the Swiss population. The survey was administered in German and French (the main languages of the country) between February 27 and March 9, 2017. ${ }^{5}$

For the experiment, we expose participants randomly to varying information about the relationship between trade and its impacts on the environment domestically and abroad. We aim with this direct treatment (Mutz 2011) to alter respondents beliefs about the environmental consequences of trade, inducing concern or serenity. We thereby address whether the relation between environmental concern and trade preferences from correlational studies (including our own) is causal in nature (Tingley 2014). This research design has an important prerequisite: environmental concern of survey respondents needs to be movable. We propose this is the case for three reasons. First, we do not aim at moving environmental concern generally (which might be sticky), but display factual information for the specific consequences of trade on the environment. Second, baseline knowledge on environmental consequences of trade is low in our survey population and citizens can therefore gain information. ${ }^{6}$ Third, knowledge (and hence information) directly constitutes part of the cognitive dimension of environmental concern (Franzen and Meyer 2009; Bamberg 2003) but is empirically also directly linked to its other components (Pagiaslis and Krontalis 2014). By changing information levels, we aim at directly manipulating, through this cognitive dimension, environmental concern (for trade impacts). Comprehension checks make sure that respondents fully read the factual information, while manipulation checks (as reported in the results section) assess whether worry for

$5 \quad$ The survey experiment was not administered to the Italian speaking part of the population in the canton of Ticino ( $4 \%$ of the country population). As reported in Appendix Figure A.8, trade attitudes and environmental concern are very similarly expressed there, on average, compared to the other two language regions. Note also that the experiment was also fielded in other countries (Nguyen, Huber and Bernauer 2021) but we focus on Swiss respondents here to ensure maximum comparability between the correlational and survey-experimental evidence.

$6 \quad$ When asked about where environmental consequences of goods consumed in Switzerland accrue, only $38 \%$ of the respondents in the first wave of the panel correctly reply "abroad", while $17 \%$ indicate "domestically" and $45 \%$ "half abroad/half domestically". 
the environmental impacts of trade indeed shifted through the experiment.

Turning to the experimental design, participants were randomly assigned to one of six groups - a control group and five treatment groups. For the treatment groups, we used a full factorial design for whether trade affects the environment in Switzerland positively or negatively, and whether it affects the environment for Switzerland's trading partners positively or negatively. As the results section focus on treatment groups 1 (trade generally "helps" the environment domestically and abroad) and 2 (trade generally "hurts"), we focus on discussing these two groups here.

Vignettes began by a general statement summarizing the main message whether trade helps or hurts the environment. Subsequently, respondents read a detailed argument on why this is the case. In conclusion, they looked at a graphical illustration that brought about the main relationship and the corresponding argument again. Figure 1 gives an overview of the flow of the argument, its exact wording and the visual appearance of the vignettes for treatment groups 1 and 2 .

Treatment groups 3, 4 and 5 saw more complicated combinations of these arguments, varying whether trade helps domestically, but hurts abroad (and vice versa). Appendix Section A.1.1 provides a comprehensive description of all treatments.

With this survey experimental manipulation we expose respondents to information on the environmental consequences of trade, with the aim of changing their beliefs about these consequences, and ultimately their concern over the environmental impacts of trade.

After exposure to the experimental vignettes, respondents answered several questions that constitute our dependent variables on beliefs, attitudes and policy preferences with regards to international trade. These include a manipulation check (perception of the relationship between trade and environment), whether respondents and the country benefit from trade, spontaneous associations respondents made with trade, and trade policy 


\section{Screen 1: Introduction}

Please read the following information. There has been some discussion about the relationship between international trade and protection of the environment. There is a lot of evidence that, overall, the effects of international trade on environmental protection both in Switzerland and in other countries with whom Switzerland trades are [positive // negative].

Screen 2A (Treatment group 1): Trade "helps" International trade creates wealth that can be used for better environmental protection in Switzerland as well as in the countries with whom Switzerland trades. International trade also promotes the development and spread of environmentally friendly technologies whose use reduces pollution and waste both in Switzerland and its trade partner countries.

In brief, international trade supports environmental protection efforts and improves environmental conditions both in Switzerland and in other countries with whom Switzerland trades.
Screen 2B (Treatment group 2): Trade "hurts"

The production and consumption of goods that are traded internationally, such as machines, steel, cement, paper, chemicals, food, metals, cars, or electronic devices damage the environment. Increased economic competition through international trade also puts pressure on policymakers to lower environmental standards both in Switzerland and in countries with whom Switzerland trades, so as to maintain the competitiveness of exporting firms. In brief, international trade undermines environmental protection efforts and worsens environmental conditions both in Switzerland and in other countries with whom Switzerland trades.

Screen 3: Graphical illustration

Please take a look at the following illustration.

Treatment group 1: Trade "helps"

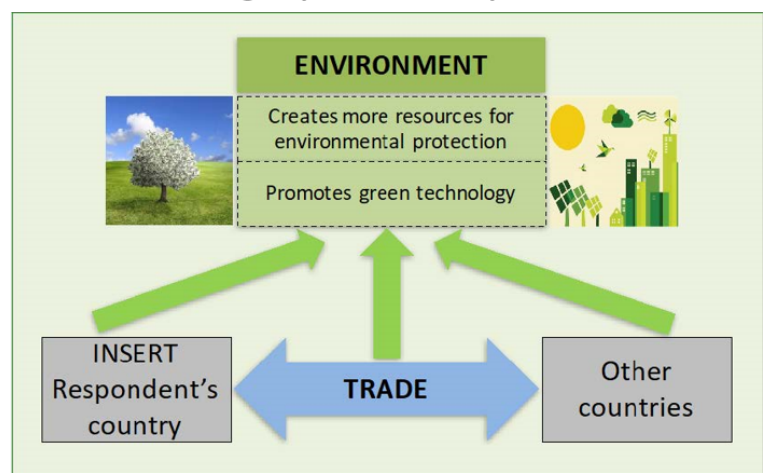

Treatment group 2: Trade "hurts"

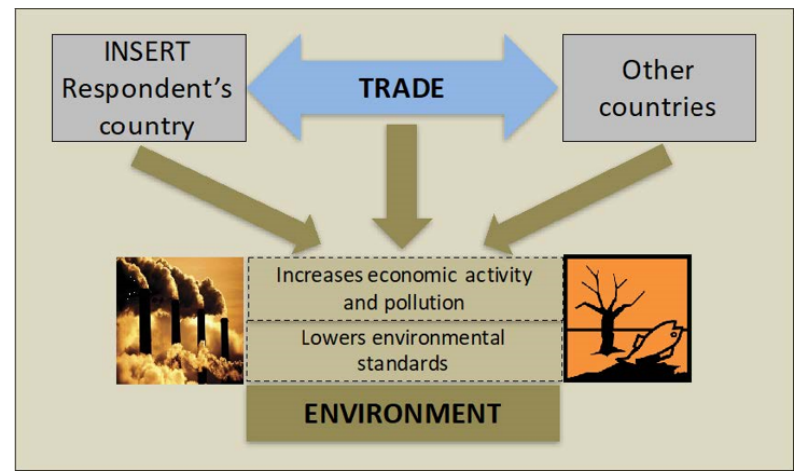

Figure 1: Flow, wording and look of vignettes for treatment groups 1 and 2 . 
preferences. Appendix Section A.1.2 provides the exact wording of these survey items. To assess subgroup effects by political ideology of the respondents, we differentiate respondents by their self-rated position on a seven-point scale ranging from left to right, asked towards the end of the survey, after the experimental manipulation and the questions on our core dependent variables. $)^{7}$

We then analyzed the data by comparing conditional means for the different vignette treatments to our control group, and also relative to each other and within subgroups defined by political ideology. Supplementary analysis (see Appendix Section A.1.3) shows that pre-treatment observable characteristics randomization worked well, as we do not see differences in respondents' observable characteristics (age, gender, language, education, employment, income, household size) between the control group and our core treatment groups 1 and 2 .

\section{Results}

\subsection{The general association of environmental concern and trade preferences in a population-representative survey}

We first investigate the general correlation between environmental concern and trade attitudes. We then inquire whether this relationship is moderated by political ideology. The main results are shown in Table 1. For the six individual trade attitude items and our aggregated measure of trade attitudes (first PCA component of these six items), we estimate ordinary least squares (OLS) models depicting the main relationship between

\footnotetext{
$7 \quad$ Question wording: 'In political matters, people talk of 'the left' and 'the right.' Generally speaking, how would you place your views on this scale? 1 means 'left' and 7 means 'right'." Respondents with an assessment of 1 to 3 are coded as left (34\% of the sample), with an assessment of 4 as center (28\%), with 5 to 7 as right (38\%).
} 
environmental concern and trade attitudes (Table 1, models 1-7.I). In a second step, we estimate OLS models that include an interaction term between environmental concern and left-right ideology (Table 1, models 1-7.II). This second step allows us to assess whether the relationship between environmental concern and trade attitudes is moderated by political ideology. Appendix Table A.5 provides the full models' specifications, and we give a short interpretation of how the covariates correlate with trade preferences in Appendix Section A.2.3.

Our key finding is that environmental concern and trade skepticism are positively correlated (Model 1.I). Looking in more detail at the different trade items (Models 2.-7.I), the correlation between environmental concern and specific trade attitudes is also in the expected direction (though insignificant for safe food access).

Substantively, the shift in trade skepticism with one unit of environmental concern is largest for protection of domestic agricultural production and smallest for safe food access. An increase of one standard deviation of environmental concern leads to an increase in trade skepticism of 0.16 standard deviations on the main dimension of trade. For the six items that comprise our aggregated measure, an increase by one standard deviation of environmental concern leads to an increase in trade skepticism ranging from 0.03 to 0.20 standard deviations of the respective trade items. ${ }^{8}$

We now turn to the effect of political ideology as moderating variable, i.e., we specify an interaction term between a respondents' environmental concern score and her leftright self-evaluation. For the main dimension of trade, the interaction term between environmental concern and political ideology is close to zero and statistically insignificant (Model 1.II). This result seems to be at odds with prior literature (Bechtel, Bernauer

$8 \quad$ Respondents who are politically more conservative are also more trade skeptic. The coefficient of political ideology is positive for all items (the relationship is insignificantly estimated for the economic openness for companies, and the price and quality dimensions). 


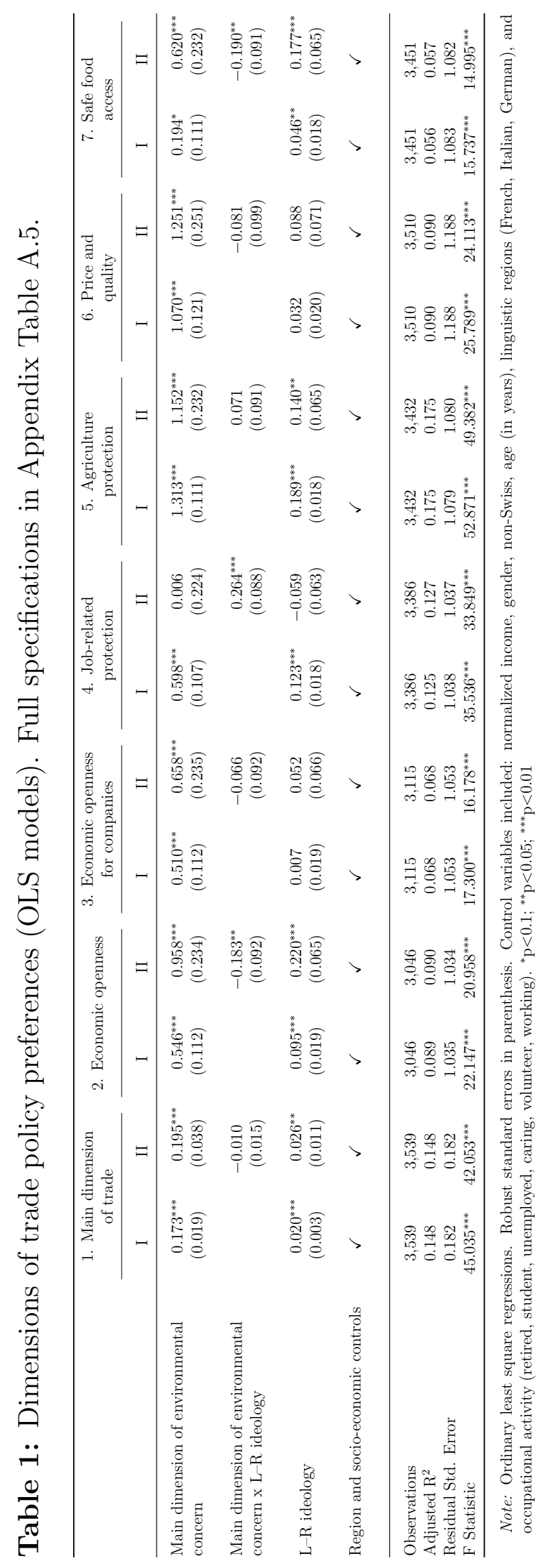


and Meyer 2012), where moderation by political ideology plays an important role. When assessing the moderating effect for specific trade items, we find substantial moderation for several items (Models 2.-7.II). Moreover, the coefficients point in a positive direction for some (the 'protectionist' trade attitudes), and a negative direction for the others (the rest, especially trade attitudes reflecting 'globalization skepticism'). This is to say that the null-finding for the interaction term in Model 1.II comes about by aggregating the individual trade items in our main dimension of trade, where the moderating effects for the individual trade items cancel out. The interaction term is significant at the $5 \%$ level for the economic openness, job-related protection, and safe food access dimensions.

To interpret substantive effect sizes, we computed average marginal effects (see Figure 2) of environmental concern conditional on left-right $(\mathrm{L}-\mathrm{R})$ political ideology for the six trade items. For the two items measuring attitudes towards economic openness, the concern for the environment has a greater impact on the trade skepticism on the political left than on the right. The same effect can be observed for the price and quality dimension. The opposite trend appears for the dimensions of trade related to the protection of jobs and agriculture: the effect of environmental concern on trade skepticism is stronger for conservative respondents. 

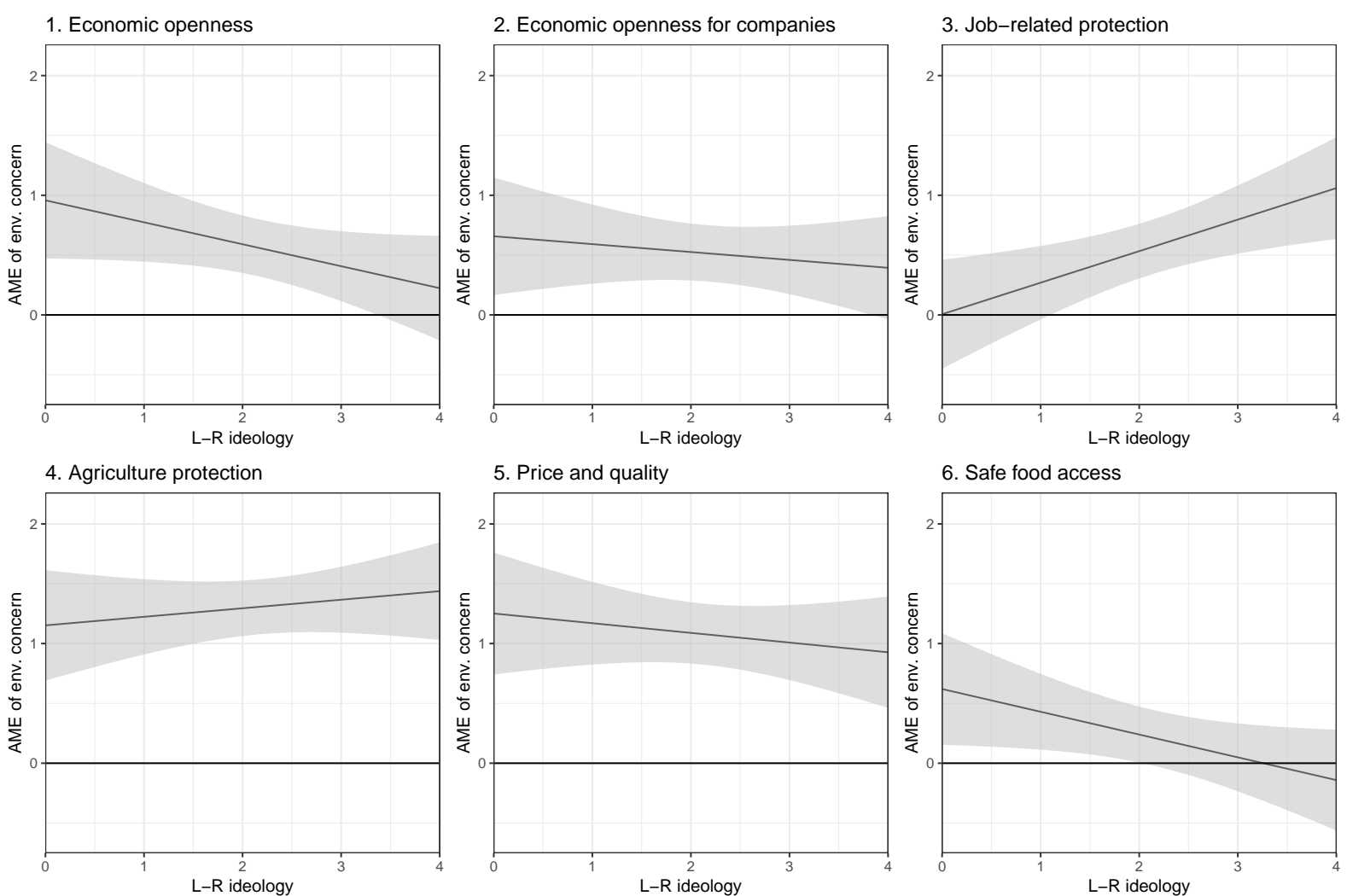

Figure 2: Average marginal effects of environmental concerns on attitudes towards six dimensions of trade. Effects are computed based on OLS estimates from models II (see Table 1). The shaded areas indicate the $95 \%$ confidence intervals computed with robust standard errors.

Finally, we conducted a series of robustness checks regarding our modelling choices and report these in Appendix Section A.2.4. They support our main findings. The interaction effects are slightly larger and still significant when using the additive index for environmental concern instead of a PCA as in Bechtel, Bernauer and Meyer (2012). We also used dichotomized dependent variables with a probit model and removed the $\mathrm{L}-\mathrm{R}$ political ideology variable from Model I. In all these specifications, the coefficients for environmental concern and the interaction term point in the expected direction. Taking into account recent critique regarding the robustness of linear interaction effects and building on Hainmueller, Mummolo and Xu (2019), we apply descriptive visualization techniques and a 
binning estimator to show that it is reasonable to build a linear interaction model for our analyses, although the results for the outcome variables economic openness for companies and safe food access should be interpreted with caution (see Appendix Section A.2.5).

\subsection{A survey experimental stimulus to environmental concern}

We next investigate very specific prompts on the relationship between trade and the environment. Respondents receive treatments whether trade has a negative or positive impact on the environment at home and/or abroad. Hence, we change respondents beliefs over the environmental impacts of trade. Thereby, we also want to induce specific concern ("hurts-treatment") or serenity ("helps-treatment") over this environmental impact. We then investigate whether this affects how respondents see the benefits from trade and their trade preferences. Table 2 summarizes the effects of the hurts- and help-treatment on a bundle of outcomes, measured on Likert scales from 1 (very negative) to 7 (very positive). Model 1 presents the results of a manipulation check. When asked "What overall effects will international trade have on environmental protection?", respondents assess the effects of trade on environmental protection rather negatively (mean of 3.2 in the control group). Our experimental vignettes do shift respondent opinions in the expected direction. The vignette that highlights that "trade helps the environment domestically and abroad" (hereafter helps-treatment) shifts respondent evaluations upwards to a neutral position on average (mean of 4.1, i.e., an increase of $26 \%$ of the control group mean). In comparison, the vignette that highlights that "trade hurts the environment domestically and abroad" (hereafter hurts-treatment) makes respondents' assessments more negative (mean of 3.0, i.e., a decrease of $5 \%$ of the control group mean, not statistically significant).

Next, we turn to the question whether these treatments affect respondents perceptions 
Table 2: Effects of survey experimental treatments on perceptions of trade and trade policy preferences

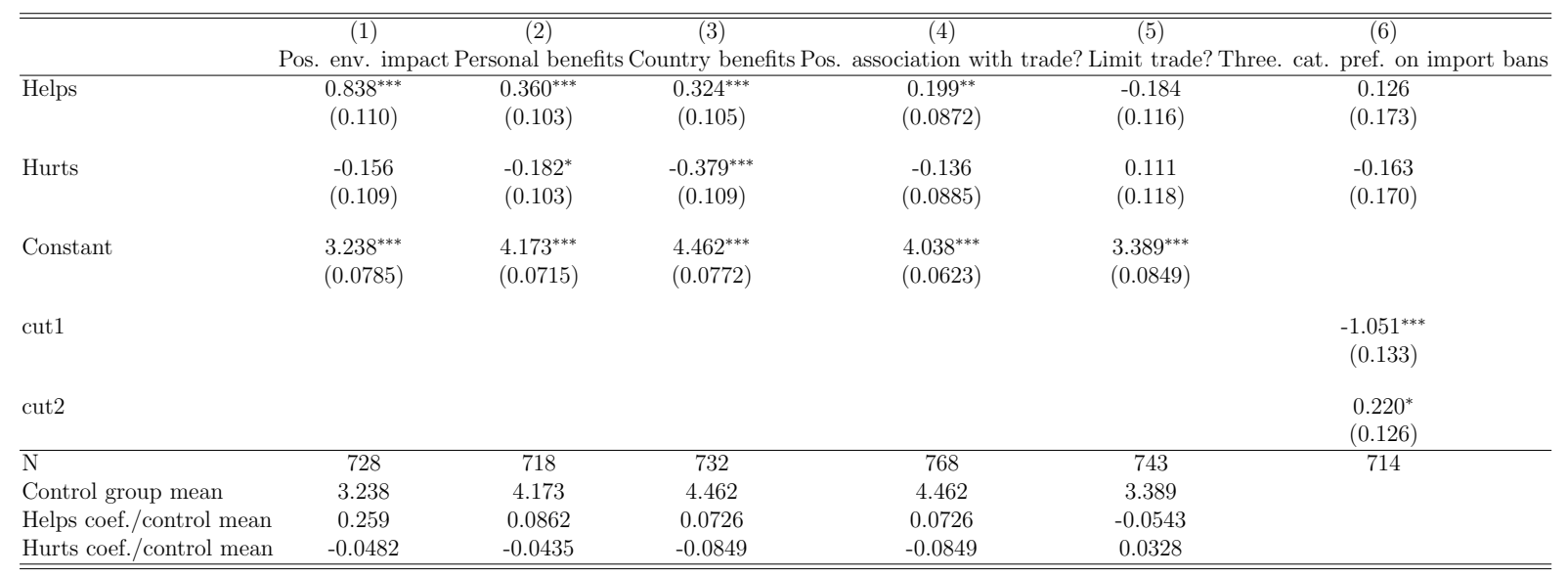

Effect of experimental treatments on average evaluation of dependent variable indicated in column header. OLS used for models 1-5; ordered logistic regression used for model 6. Dependent variables are: 1: "What overall effects will international trade have on environmental protection?" 2: "What do you think about the growing trade and business ties between Switzerland and other countries [for] myself and my family?"; 3: “... [for] Switzerland as a country?"; 4: index from replies to association questions ("spontaneously", what is "the first thing that comes to your mind when you hear about international trade"?) concerning bad-good, threat-opportunity, unemployment-jobs, fear-hope, poverty-wealth, unfair-fair; 5: "Limit inter-national trade to reduce negative environmental consequences"; 6: "Do you favor or oppose new limits on imports, or haven't you thought much about this?". Answer scales 1 (negative) to 7 (positive) for models 1-4, 1 (disagree) to 6 (agree) for model 5, three-categorical scale "favor", "not thought much about it", "oppose" for model 6 . Robust standard errors used. "** $p<0.01,{ }^{* *} p<0.05$, ${ }^{*} p<0.10$

of trade. Model 2 and 3 show that the helps-treatment causes respondents to assess both the personal and the country benefits from international trade as more favorable compared to the control group. When trade is communicated to help the environment domestically and abroad, this increases the perceived personal benefits from trade by 0.36 ( $9 \%$ of the control group mean, significant at the $1 \%$ level). In comparison, when we communicate that trade hurts the environment domestically and abroad, this decreases perceived personal benefits by 0.18 (4\% of the control group mean, significant at the $10 \%$ level). Respondents react slightly stronger with respect to perceived country benefits from trade, where the helps-treatment increases the average response by $0.32(7 \%$ of the control group mean, significant at the $1 \%$ level). We see a similarly strong effect of the hurts-treatment, decreasing perceived country benefits by 0.38 ( $8 \%$ of the control group mean, significant at the $1 \%$ level). Note also that in absolute terms respondents perceive country benefits from trade as more substantial compared to personal benefits. 
Our treatments, and the induced concern for the environmental impacts of trade, affect attitudes towards trade more broadly. As presented in Model 4, the helps-treatment causes respondents to spontaneously associate trade with a broad range of more favorable associations like opportunities, jobs, hope, wealth or fairness. The hurts-treatment works in the opposite direction, though not at conventional levels of statistical significance. Concerning the individual items contained in the index, effects emerge for the hurtstreatment, which causes respondents to see more "threats" and assess trade as rather "bad", and for the helps-treatment, causing respondents to relate trade with more "hope" and "wealth". 


\section{Subgroup effects by ideology}
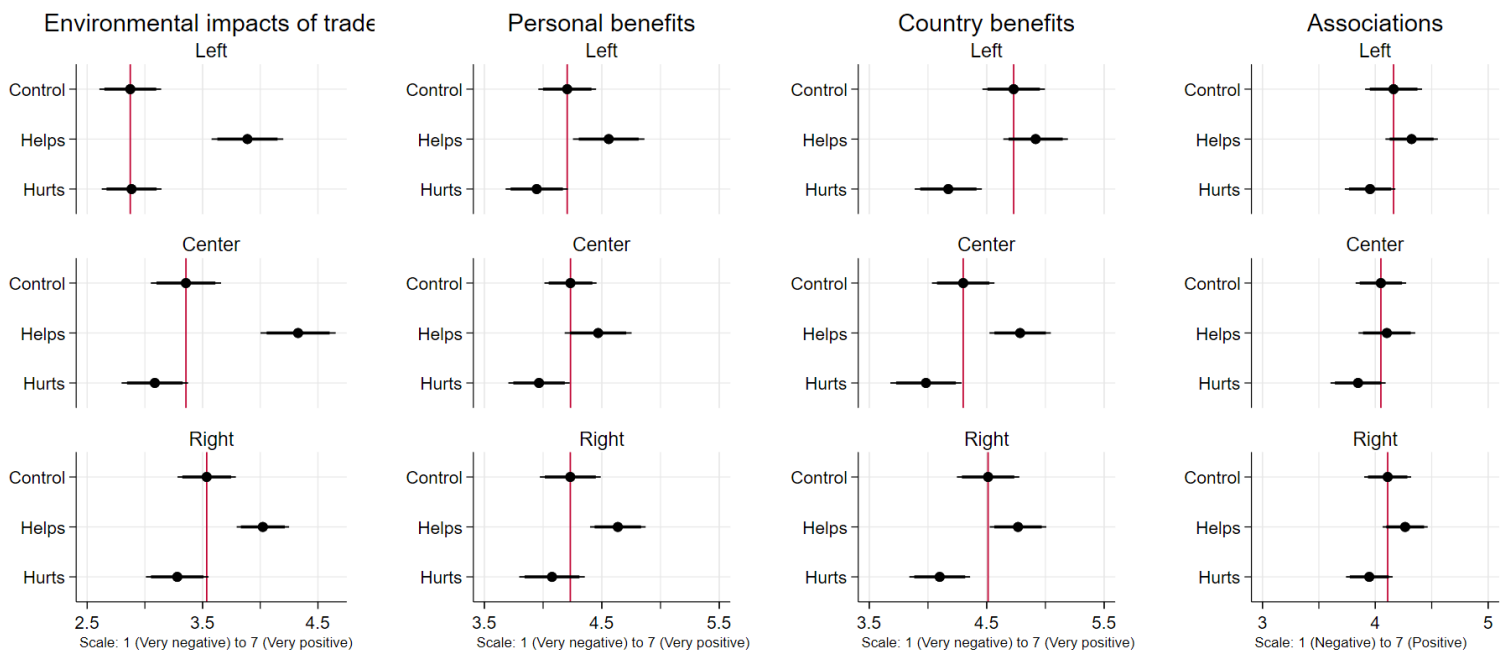

Figure 3: Average response by treatment condition for subgroups of political ideology. Panel 1: "What overall effects will international trade have on environmental protection?" Panel 2: "What do you think about the growing trade and business ties between Switzerland and other countries [for] myself and my family?"; Panel 3: “... [for] Switzerland as a country?"; Panel 4: index from replies to association questions ("spontaneously", what is "the first thing that comes to your mind when you hear about international trade"?) concerning bad-good, threat-opportunity, unemployment-jobs, fear-hope, poverty-wealth, unfair-fair. Answer scales 1 (negative) to 7 (positive). $90 \%$ and $95 \%$ confidence intervals computed with robust standard errors shown. Vertical lines indicate control-group means.

Before discussing implications for trade policy preferences, we shortly turn to how these perceptions play out for the political left and right. As can be seen from Figure 3, respondents on the political left and right show similar baseline evaluations of these perception questions. Notably, the control group evaluation of trade impacts is substantially more negative for the political left (mean of 2.9) compared to the political right (mean of 3.5). Concerning treatment effects, the treatments work in the expected direction in all subgroups (except for the hurts-treatment in panel 1 of Figure 3 for the political left, and not always showing significant differences, which might also be due to small subgroup 
sample sizes).

Now, we turn to how concern for the environmental impacts of trade affects trade policy attitudes. Respondents are on average torn between limiting or not limiting international trade to reduce negative environmental consequences, with left-leaning respondents rather for, and center- and right-leaning respondents rather against trade limits (Model 5 of Table 2 and left panel of Figure 4). Looking at the experimental vignettes, our treatment effects are substantively small and mostly not statistically significant. The treatment communicating that trade helps the environment domestically and abroad moves respondents to disapprove trade limits by 0.18 scale points (p-value $0.11,5 \%$ of the control group mean, column 5), whereas the hurts-treatment leads to respondents being more likely to approve them by 0.11 points (p-value $0.34,3 \%$ of the control group mean) relative to the control group. Concerning subgroup effects, we find that respondents on the political left respond strongly to specific treatments. They are more likely to disagree with trade limits given the helps-treatment (by half a scale-point, $13 \%$ of control group mean).

Finally, we look at replies to a categorical variable assessing a proposal to introduce import bans (Model 6 of Table 2). While results are statistically insignificant for most models, the direction of effects is insightful. Overall, we find small shifts towards preferences for free trade for the helps-, and small shifts towards trade restrictions for the hurts-treatment. Concerning subgroups (right panel of Figure 4), those leaning towards the political left are moved towards favoring free trade by the helps-treatment, while those leaning towards the political right are moved towards restricting trade. Those in the political center are unmoved by the treatments. These effects, while only significant (on the $10 \%$ level) for the political right, are sizable. With the helps-treatment, more than $50 \%$ of the respondents on the political left favor free trade. With the hurts-treatment, less than $50 \%$ of respondents on the political right favor free trade. 


\section{Subgroup effects by ideology}
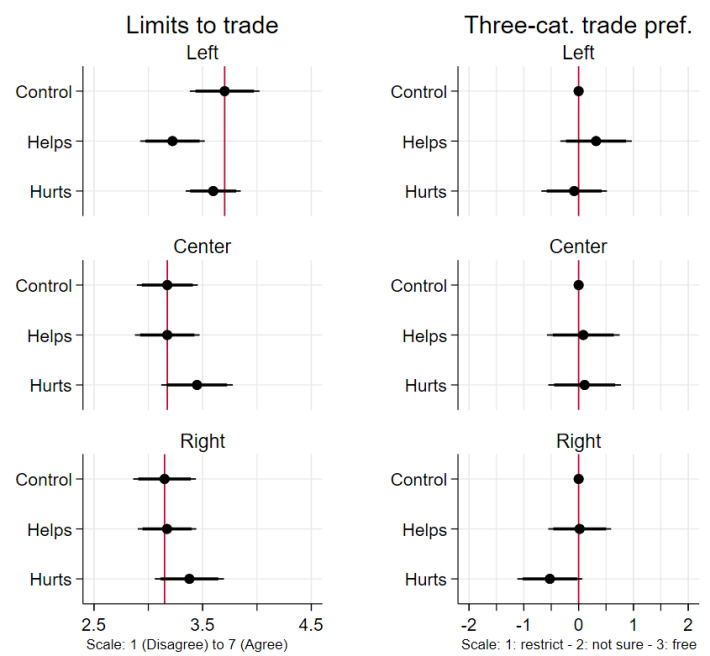

Figure 4: Left panel: Average reply to question "Limit international trade to reduce negative environmental consequences" (7-point scale) by treatment condition for subgroups of political ideology. Right panel: Coefficient from ordered logistic regression of question "Do you favor or oppose new limits on imports, or haven't you thought much about this?" on treatment condition by subgroups of political ideology. $90 \%$ and $95 \%$ confidence intervals computed with robust standard errors shown. Vertical lines indicate control-group means.

In summary, the experimental results show that negative or positive information on the environmental implications of trade affects respondents' beliefs on the environmental implications of trade, both in a negative and, more so, in a positive direction. Experimentally induced variation in beliefs over the positive environmental impact of trade causes a more positive perception of both personal and country benefits from trade and leads to more negative feelings towards trade, and vice versa. We also find some tentative evidence that this also affects trade policy preferences. Shifts are particularly strong for left-leaning respondents who received the helps-treatment and right-leaning respondents who received the hurts-treatment. One explanation for this finding is that such information cuts against existing beliefs of the subgroups prior to treatment. Taken together, our 
experiment shows that the environmental implications of trade affect trade preferences.

Appendix Section A.1.4 offers additional evidence for three more complex treatment vignettes. These treatments highlighted that environmental effects of trade are positive, (1) but only for the home country, (2) but only for trading partners abroad, or (3) but only for the home country with an extended explanation of footprint shifting. With these more complex and differentiated treatments, we see only a few significant changes in the evaluation of trade, its effects, or policy preferences. We return to this issue in the discussion section.

\section{Discussion}

While political economy research on the trade-environment relationship was focused on territorial measures of pollution and other forms of environmental degradation, it generated ambiguous empirical findings, notably for the pollution haven claim (Spilker, Koubi and Bernauer 2017). Life cycle analysis, which emanates from environmental sciences and engineering, has shifted our focus from territorial (production) to consumption-based environmental outcome measures (Aklin 2016; Lutter et al. 2016). With this changed focus, there is strong evidence that trade and the associated global supply chains are a large and powerful driver of environmental burden allocation in the global economy, and that there is a major international pollution haven issue in this regard (Wiedmann and Lenzen 2018).

Such scientific findings are obviously important. Nevertheless, their policy implications hinge on attitudes and preferences of the mass public, because democratic policymakers are very likely to act at least broadly in line with what citizens want (Wlezien and Soroka 2007), as long as preferences shift with policy (Wlezien 2017). This puts public opinion research on the trade-environment relationship on center stage. Indeed, 
the trade-environment relationship has become very salient in various policy-making contexts, ranging from the TTIP to Brexit and controversy over the design of environmental clauses in preferential trade agreements (Chan and Crawford 2017; Hübner, Deman and Balik 2017; Lechner 2016; Blümer et al. 2019).

The findings we reported in this paper show that environmental concern and trade skepticism are causally related. They complement earlier research that has pointed in this direction (Bechtel, Bernauer and Meyer 2012; Nguyen and Bernauer 2015; Spilker, Bernauer and Umaña 2018). Our experimental results show that an increase in concern about the environmental impacts of trade leads to a worse evaluation of trade benefits, worse implicit feelings towards trade, and support for more restrictive trade policy. However, because the extent to which environmental concern can be manipulated in an experiment is limited, the correlational evidence we use complements the experimental findings. It supports the experimental results: citizens with higher degrees of environmental concern are more trade skeptic on average.

Our findings suggest that policymakers should pay more attention to the greening of global supply chains if they wish to sustain public support for liberal international trade policy (EC 2019). Our findings are also analytically useful in terms of helping us make sense of the current backlash against economic globalization (Walter 2021; Naoi 2020; Mansfield, Milner and Rudra 2021), increasingly elaborate environmental clauses in trade agreements (Bastiaens and Postnikov 2019; Jinnah and Morin 2020), and attempts in the private sector at greening international supply chains (Thorlakson, Zegher and Lambin 2018; Bastiaens and Postnikov 2019).

Further, our results show that ecologically motivated skepticism about trade liberalization resonates both on the political left and right, with some nuances concerning particular facets of trade and trade policy. Most respondents in our sample have only a 
limited awareness of how large their country's environmental footprint is abroad, relative to the domestic level (see section 2.2). We believe that increasing public awareness of the environmental impacts that domestic consumption has abroad is likely to lead to an even stronger effect of environmental concern on trade skepticism over the coming years. The reason is that our experimental results suggest that there is little home bias in how citizens perceive the trade-environment relationship - one might have suspected that particularly citizens on the political right will be less worried about offloading environmental impacts on other countries, but this is not the case.

The combination of correlational and experimental evidence implies that our results are likely to have high internal validity. Assessing to what extent our results are relevant for other countries will require additional research, and our study hopefully provides a useful template for this. It is noteworthy, however, that Swiss citizens hold very similar levels of environmental concern and perceptions of personal trade impact and trade policy preferences as citizens in other high-income countries. ${ }^{9}$ This suggests that using a similar or even identical study design in other high-income democratic countries may well produce similar findings.

Finally, the survey-experimental part of our study is not designed to clearly distinguish informational effects from framing effects (the latter "understood to mean a communicator's selective presentation and interpretation of an issue [, the former as] argument-based persuasion", Leeper and Slothuus 2018, p. 2). This distinction could be relevant when trying to establish the implications our research may have for how easily citizens attitudes could be moved by political actors (see Leeper and Slothuus 2018). We cannot ascertain directly to what extent respondents take up our survey-experimental treatments as emphasis of pieces of information they already have in mind or of new information. Given

$9 \quad$ In Appendix Section A.4.2 we show these similarities based on data from ISSP Research Group (2019) and Nguyen, Huber and Bernauer (2021). 
low levels of knowledge on the allocation of environmental footprints of Swiss consumption (see section 2.2), it is likely that at least a relevant part of our treatment affects study participants through information provision and its subsequent effect on the cognitive dimension of environmental concern. However, future research could investigate to what extent survey-experimental treatments on the environmental consequences of trade only affect the weights with which different pieces of information that citizens already possess enter the attitude or preference formation calculus, or to what extent they affect information levels as such. To this end, surveys (ideally in panel format) that assess information levels and trade attitudes at one point in time, provide factual information and then reassess trade attitudes at a later point in time could be useful.

As of now, there is only little research on the trade-environment nexus from a public opinion perspective. We hope that our research encourages similar studies in other countries, which will be important for assessing the relevance of our arguments and findings in other cultural and political contexts. 


\section{References}

Aklin, Michaël. 2016. "Re-Exploring the Trade and Environment Nexus Through the Diffusion of Pollution." Environmental and Resource Economics 64(4):663-682.

Anderson, Brilé, Tobias Böhmelt and Hugh Ward. 2017. "Public opinion and environmental policy output: a cross-national analysis of energy policies in Europe." Environmental Research Letters 12(11):114011.

Bamberg, Sebastian. 2003. "How does environmental concern influence specific environmentally related behaviors? A new answer to an old question." Journal of environmental psychology 23(1):21-32.

Bastiaens, Ida and Evgeny Postnikov. 2019. "Social standards in trade agreements and free trade preferences: An empirical investigation." The Review of International Organizations pp. 1-24.

Bauer, Paul C, Pablo Barberá, Kathrin Ackermann and Aaron Venetz. 2017. "Is the left-right scale a valid measure of ideology?" Political Behavior 39(3):553-583.

Bearce, David H and Samantha L Moya. 2020. "Why is the Mass Public Not More Supportive of Free Trade? Evidence from the United States." International Studies Quarterly 64(2):380-391.

Bechtel, Michael M., Thomas Bernauer and Reto Meyer. 2012. "The green side of protectionism: Environmental concerns and three facets of trade policy preferences." Review of International Political Economy 19(5):837-866.

Ben-David, Dan and Michael B. Loewy. 1998. "Free Trade, Growth, and Convergence." Journal of Economic Growth 3(2):143-170. 
Blümer, Dominique, Jean-frédéric Morin, Clara Brandi and Axel Berger. 2019. "Environmental provisions in trade agreements: defending regulatory space or pursuing offensive interests?" Environmental Politics forthcoming:1-24.

Burgoon, Brian. 2009. "Globalization and backlash: Polayni's revenge?" Review of International Political Economy 16(2):145-177.

Chan, Alexsia T and Beverly K Crawford. 2017. "The puzzle of public opposition to TTIP in Germany." Business and Politics 19(4):683-708.

Copeland, Brian and M. Scott Taylor. 2003. Trade, Growth and the Environment. Technical Report w9823 National Bureau of Economic Research.

Czarnek, Gabriela, Małgorzata Kossowska and Paulina Szwed. 2021. "Right-wing ideology reduces the effects of education on climate change beliefs in more developed countries." Nature Climate Change 11(1):9-13.

Dunlap, Riley E. 1975. "The impact of political orientation on environmental attitudes and actions." Environment and behavior 7(4):428-454.

Dür, Andreas and Gemma Mateo. 2014. "Public opinion and interest group influence: how citizen groups derailed the Anti-Counterfeiting Trade Agreement." Journal of European Public Policy 21(8):1199-1217.

Dutt, Pushan and Devashish Mitra. 2005. "Political ideology and endogenous trade policy: an empirical investigation." Review of Economics and Statistics 87(1):59-72.

Dür, Andreas and Gemma Mateo. 2014. "Public opinion and interest group influence: how citizen groups derailed the Anti-Counterfeiting Trade Agreement." Journal of European Public Policy 21(8):1199-1217. 
EC. 2019. "Eurobarometer survey: Majority of EU citizens positive about international trade." European Commission Press Rele.

Ehrlich, Sean D. 2010. "The Fair Trade Challenge to Embedded Liberalism." International Studies Quarterly 54(4):1013-1033.

Ehrlich, Sean D. 2018. The politics of fair trade: Moving beyond free trade and protection. Oxford University Press.

Eliasson, Leif Johan and Patricia Garcia Duran Huet. 2018. "TTIP negotiations: Interest groups, anti-TTIP civil society campaigns and public opinion." Journal of Transatlantic Studies 16(2):101-116.

Eurobarometer. 2019. Special Eurobarometer 291 - Europeans' attitudes on trade and EU Trade policy. European Commission.

Fortunato, David, Randolph T Stevenson and Greg Vonnahme. 2016. "Context and political knowledge: Explaining cross-national variation in partisan left-right knowledge." The Journal of Politics 78(4):1211-1228.

Franzen, Axel and Reto Meyer. 2009. "Environmental Attitudes in Cross-National Perspective: A Multilevel Analysis of the ISSP 1993 and 2000." European Sociological Review 26(2):219-234.

Goldsmith, Benjamin E and Yusaku Horiuchi. 2012. "In search of soft power: Does foreign public opinion matter for US foreign policy?" World Politics 64(3):555-585.

Hainmueller, Jens, Jonathan Mummolo and Yiqing Xu. 2019. "How much should we trust estimates from multiplicative interaction models? Simple tools to improve empirical practice." Political Analysis 27(2):163-192. 
Hainmueller, Jens and Michael J. Hiscox. 2006. "Learning to love globalization: Education and individual attitudes toward international trade." International Organization 60(2):469-498.

Hänggli, Regula and Silja Häusermann. 2015. "Consensus lost? Disenchanted democracy in Switzerland." Swiss Political Science Review 21(4):475-490.

Hertwich, Edgar G. and Glen P. Peters. 2009. "Carbon footprint of nations: A global, trade-linked analysis." Environmental Science and Technology 43(16):6414-6420.

Hoekstra, A. Y. and T. O. Wiedmann. 2014. "Humanity's unsustainable environmental footprint." Science 344(6188):1114-1117.

Hübner, Kurt, Anne-sophie Deman and Tugce Balik. 2017. "EU and trade policy-making : the contentious case of CETA." Journal of European Integration 6337:1-15.

ISSP Research Group. 2019. "International Social Survey Programme: Environment III - ISSP 2010.” GESIS Datenarchiv, Köln. ZA5500 Datenfile Version 3.0.0, https://doi.org/10.4232/1.13271.

Jedinger, Alexander and Axel M Burger. 2020. "The ideological foundations of economic protectionism: Authoritarianism, social dominance orientation, and the moderating role of political involvement." Political Psychology 41(2):403-424.

Jinnah, Sikina and Jean-Frédéric Morin. 2020. Greening through trade: How American trade policy is linked to environmental protection abroad. Mit Press.

Jorgenson, Andrew A. and James Rice. 2005. "Structural Dynamics of International Trade and Material Consumption: A Cross-National Study of the Ecological Footprints of Less-Developed Countries." Journal of World-Systems Research 11(1):57. 
Kaltenthaler, Karl C., Ronald D. Gelleny and Stephen J. Ceccoli. 2004. "Explaining citizen support for trade liberalization." International Studies Quarterly 48(4):829-851.

Kanemoto, K., D. Moran, M. Lenzen and A. Geschke. 2014. "International trade undermines national emission reduction targets: New evidence from air pollution." Global Environmental Change 24(1):52-59.

Kertzer, Joshua D. and Thomas Zeitzoff. 2017. "A Bottom-Up Theory of Public Opinion about Foreign Policy: A BOTTOM-UP THEORY OF PUBLIC OPINION ABOUT FOREIGN POLICY." 61(3):543-558.

Kono, Daniel Y. 2008. "Does Public Opinion Affect Trade Policy?" Business and Politics 10(2):1-19.

Lechner, Lisa. 2016. "The domestic battle over the design of non-trade issues in preferential trade agreements." Review of International Political Economy 23(5):840-871.

Leeper, Thomas J and Rune Slothuus. 2018. "Can Citizens Be Framed? How Persuasive Information More than Emphasis Framing Changes Political Opinions.".

Lutter, S., S. Pfister, S. Giljum, H. Wieland and C. Mutel. 2016. "Spatially Explicit Assessment of Water Embodied in European Trade: A Product-Level Multi-Regional Input-Output Analysis." Global Environmental Change 38:171-182.

Mansfield, Edward D and Diana C Mutz. 2009. "Support for free trade: Self-interest, sociotropic politics, and out-group anxiety." International Organization 63(3):425-457.

Mansfield, Edward D, Helen V Milner and Nita Rudra. 2021. "The Globalization Backlash: Exploring New Perspectives." Comparative Political Studies p. 00104140211024286. 
Maria Schaffer, Lena and Gabriele Spilker. 2019. "Self-interest versus sociotropic considerations: An information-based perspective to understanding individuals' trade preferences." Review of International Political Economy 26(6):1266-1292.

Milner, Helen V. and Benjamin Judkins. 2004. "Partisanship, Trade Policy, and Globalization: Is There a Left-Right Divide on Trade Policy?" International Studies Quarterly 48(1):95-119.

Milner, Helen V and Dustin H Tingley. 2011. "Who supports global economic engagement? The sources of preferences in American foreign economic policy." International Organization 65(1):37-68.

Milner, Helen V and Dustin Tingley. 2013. "Public opinion and foreign aid: A review essay." International Interactions 39(3):389-401.

Morin, Jean-Frédéric, Andreas Dür and Lisa Lechner. 2018. "Mapping the Trade and Environment Nexus: Insights from a New Data Set." Global Environmental Politics 18(1):122-139.

Mutz, Diana C. 2011. Population Based Survey Experiments. Princeton: Princeton University Press.

Naoi, Megumi. 2020. "Survey Experiments in International Political Economy: What We (Don't) Know About the Backlash Against Globalization." Annual Review of Political Science pp. 1-24.

Nguyen, Quynh, Robert A Huber and Thomas Bernauer. 2021. "Environmental Impacts and Public Opinion About International Trade: Experimental Evidence from Six OECD Countries." Global Environmental Politics pp. 1-28. 
Nguyen, Quynh and Thomas Bernauer. 2015. "Free Trade and/or Environmental Protection?" Global Environmental Politics 15(4):105-129.

Pagiaslis, Anastasios and Athanasios Krystallis Krontalis. 2014. "Green consumption behavior antecedents: Environmental concern, knowledge, and beliefs." Psychology $\&$ Marketing 31(5):335-348.

Rho, Sungmin and Michael Tomz. 2017. "Why don't trade preferences reflect economic self-interest?" International Organization 71(S1):S85-S108.

Rodrik, Dani. 2018. "Populism and the economics of globalization." Journal of International Business Policy 1(1-2):12-33.

Sabet, Shahrzad. 2016. "Feelings First : Non-Material Factors as Moderators of Economic Self-Interest." mimeo .

Scheve, Kenneth F and Matthew J Slaughter. 2001. "What determines individual tradepolicy preferences?" Journal of International Economics 54(2):267-292.

Spilker, Gabriele, Thomas Bernauer and Víctor Umaña. 2018. "What Kinds of Trade Liberalization Agreements Do People in Developing Countries Want?" International Interactions 44(3):510-536.

Spilker, Gabriele, Vally Koubi and Thomas Bernauer. 2017. "International Political Economy and the Environment.".

Thorlakson, Tannis, Joann F De Zegher and Eric F Lambin. 2018. “Companies' contribution to sustainability through global supply chains." Proceedings of the National Academy of Sciences 115(9):2072-2077. 
Tingley, Dustin. 2014. "Survey Research in International Political Economy: Motivations, Designs, Methods." International Interactions 40(3):443-451.

Vandeweerdt, Clara, Bart Kerremans and Avery Cohn. 2016. "Climate voting in the US Congress: the power of public concern." Environmental Politics 25(2):268-288.

Walter, Stefanie. 2021. "The backlash against globalization." Annual Review of Political Science 24:421-442.

Weaver, Alicia A. 2008. "Does protest behavior mediate the effects of public opinion on national environmental policies? A simple question and a complex answer." International Journal of Sociology 38(3):108-125.

Wiedmann, Thomas and Manfred Lenzen. 2018. "international trade." Nature Geoscience 11(May).

Wlezien, Christopher. 2017. The thermostatic model: The public, policy and politics. In The Routledge Handbook of Elections, Voting Behaviorand Public Opinion. Routledge pp. $404-415$.

Wlezien, Christopher and Stuart N Soroka. 2007. The relationship between public opinion and policy. In The Oxford handbook of political behavior.

Wood, Richard, Konstantin Stadler, Moana Simas, Tatyana Bulavskaya, Stefan Giljum, Stephan Lutter and Arnold Tukker. 2018. "Growth in Environmental Footprints and Environmental Impacts Embodied in Trade: Resource Efficiency Indicators from EXIOBASE3." Journal of Industrial Ecology 22(3):553-564.

Yang, Yi, Junghan Bae, Junbeum Kim and Sangwon Suh. 2012. "Replacing gasoline with corn ethanol results in significant environmental problem-shifting." Environmental Science and Technology 46(7):3671-3678. 


\section{Online Appendix for 'Environmental concern leads to trade skepticism on the political left and right'}

\section{A.1 Supporting information for survey-experimental study}

\section{A.1.1 Description of treatments}

In the experiment, we administered information to respondents on whether trade has a negative or a positive impact on the environment abroad and domestically. Responses are contrasted with a control group receiving no information on the environmental impacts of trade. Table A.1 provides an overview of the different experimental vignettes.

Table A.1: Overview of treatment conditions

\begin{tabular}{|c|c|c|c|c|c|c|}
\hline Group & Control & 1 & 2 & 3 & 4 & 5 \\
\hline $\begin{array}{l}\text { Trade affects the } \\
\text { domestic environment }\end{array}$ & No info & Helps & Hurts & Helps & Hurts & Helps \\
\hline $\begin{array}{l}\text { Trade affects the } \\
\text { environment abroad }\end{array}$ & No info & Helps & Hurts & Hurts & Helps & $\begin{array}{c}\text { Hurts } \\
\text { (extended) }\end{array}$ \\
\hline
\end{tabular}

Respondents then first read a brief verbal description of the treatment, and subsequently saw a graphical illustration that summarized the treatment they received. Respondents had to go through a comprehension check. If they did not pass this comprehension check they were asked to re-read the treatment text.

Below, we list the precise wording (translated to English) of the vignettes.

- Control group: No information given.

- Treatment group 1:

Please read the following information.

There has been some discussion about the relationship between international trade and protection of the environment.

There is a lot of evidence that, overall, the effects of international trade on environmental protection both in Switzerland and in other countries with whom Switzerland trades are positive.

\section{NEW SCREEN}

International trade creates wealth that can be used for better environmental protection in Switzerland as well as in the countries with whom Switzerland trades. International trade also promotes the development and spread of environmentally 
friendly technologies whose use reduces pollution and waste both in Switzerland and its trade partner countries.

In brief, international trade supports environmental protection efforts and improves environmental conditions both in Switzerland and in other countries with whom Switzerland trades.

\section{NEW SCREEN}

Please take a look at the following illustration:

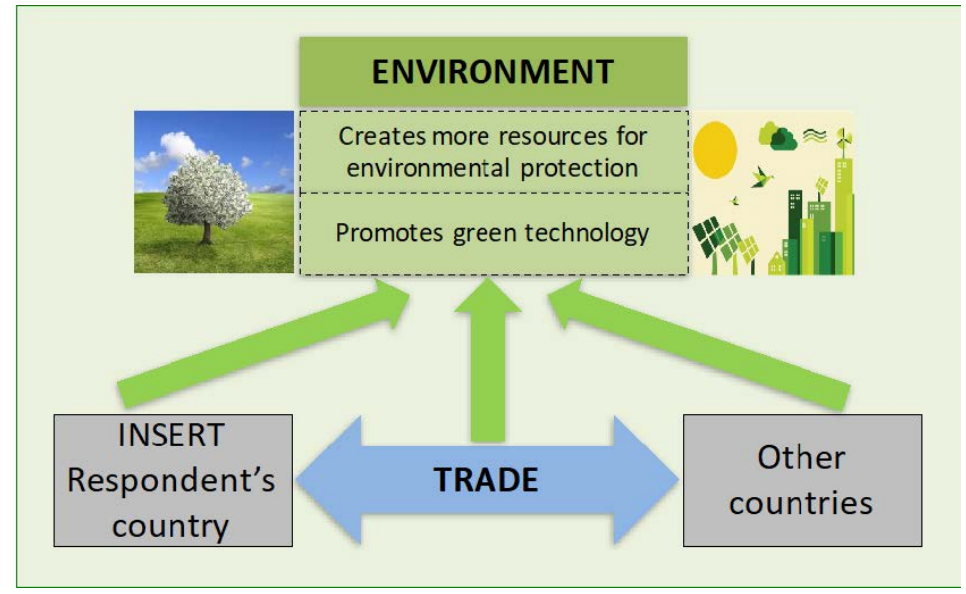

\section{- Treatment group 2:}

Please read the following information.

There has been some discussion about the relationship between international trade and protection of the environment.

There is a lot of evidence that, overall, the effects of international trade on environmental protection both in Switzerland and in other countries with whom Switzerland trades are negative.

\section{NEW SCREEN}

The production and consumption of goods that are traded internationally, such as machines, steel, cement, paper, chemicals, food, metals, cars, or electronic devices damage the environment. Increased economic competition through international trade also puts pressure on policymakers to lower environmental standards both in Switzerland and in countries with whom Switzerland trades, so as to maintain the competitiveness of exporting firms.

In brief, international trade undermines environmental protection efforts and worsens environmental conditions both in Switzerland and in other countries with whom Switzerland trades.

NEW SCREEN 
Please take a look at the following illustration:

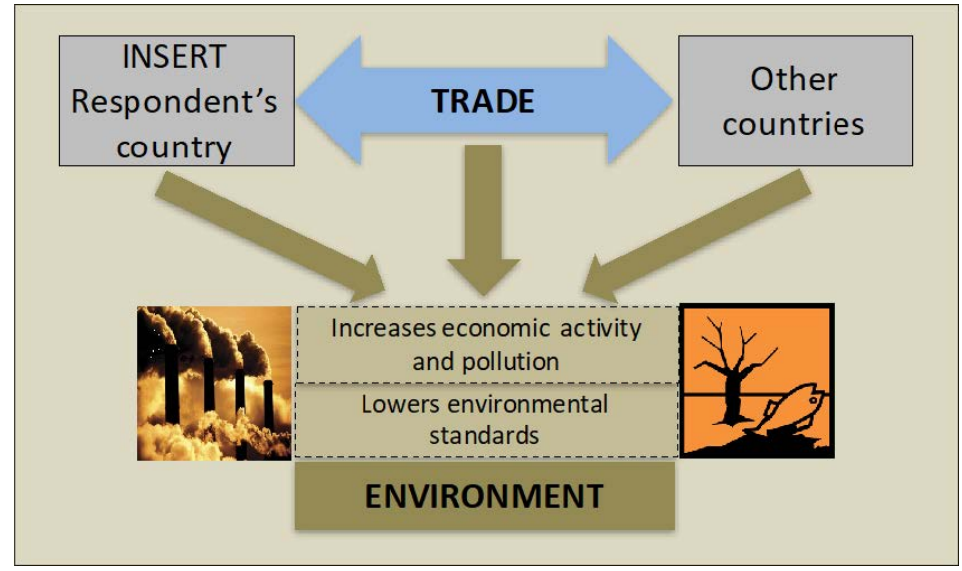

\section{- Treatment group 3:}

Please read the following information.

There has been some discussion about the relationship between international trade and protection of the environment.

There is a lot of evidence that, overall, the effects of international trade on environmental protection in Switzerland are positive, but that the effects on environmental protection in other countries with whom Switzerland trades are negative.

\section{NEW SCREEN}

On the one hand, international trade creates wealth that can be used for better environmental protection in Switzerland. International trade also promotes the development and spread of environmentally friendly technologies whose use reduces pollution and waste in Switzerland.

On the other hand, the production of goods such as machines, steel, cement, paper, chemicals, food, metals, cars, or electronic devices, which are exported from other countries to Switzerland, damages the environment in those other countries. Increased economic competition through international trade also puts pressure on policymakers in those countries to lower their environmental standards, so as to maintain the competitiveness of exporting firms.

In brief, international trade supports environmental protection efforts and improves environmental conditions in Switzerland. But it undermines environmental protection efforts and worsens environmental conditions in other countries with whom Switzerland trades.

\section{NEW SCREEN}

Please take a look at the following illustration: 


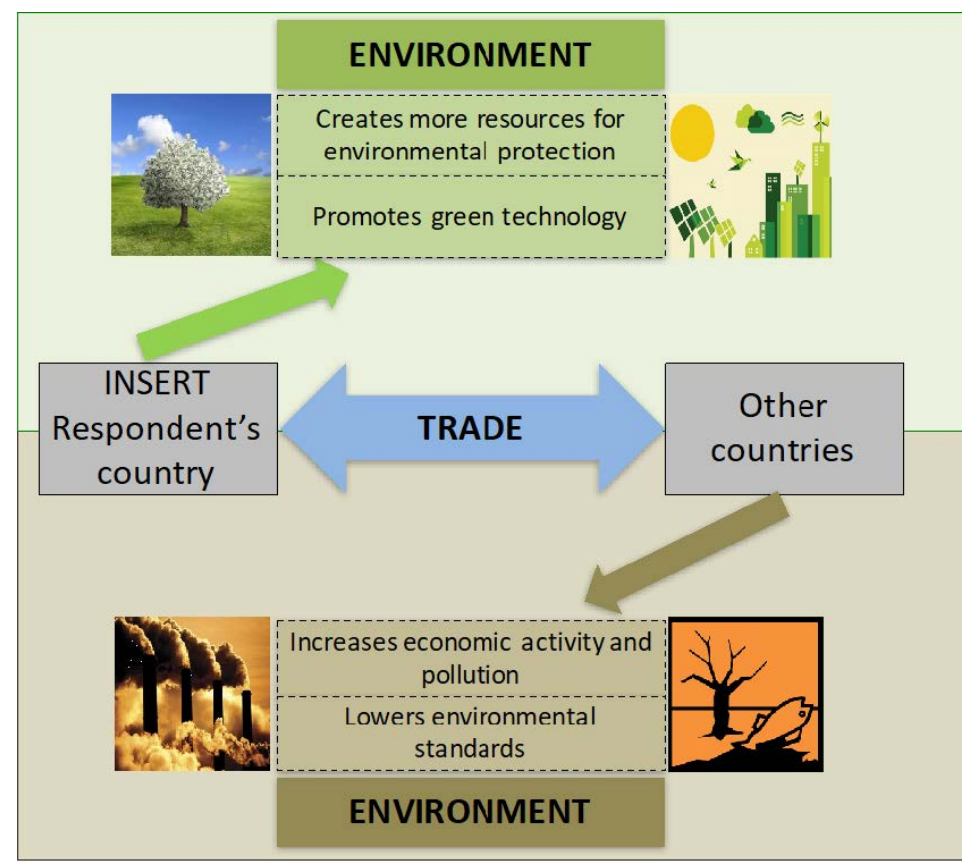

- Treatment group 4:

Please read the following information.

There has been some discussion about the relationship between international trade and protection of the environment.

There is a lot of evidence that, overall, the effects of international trade on environmental protection in Switzerland are negative, but that the effects on environmental protection in other countries with whom Switzerland trades are positive.

\section{NEW SCREEN}

On the one hand, the production of goods such as machines, steel, cement, paper, chemicals, food, metals, cars, or electronic devices, which are exported from Switzerland to other countries, damages the environment in Switzerland. Increased economic competition through international trade also puts pressure on policymakers in Switzerland to lower environmental standards, so as to maintain the competitiveness of exporting firms.

On the other hand, in other countries with whom Switzerland trades, international trade creates wealth that can be used for better environmental protection. International trade also promotes the development and spread of environmentally friendly technologies whose use reduces pollution and waste in those countries.

In brief, international trade undermines environmental protection efforts and worsens environmental conditions in Switzerland, but supports environmental protection efforts and improves environmental conditions in other countries with whom Switzerland trades. 


\section{NEW SCREEN}

Please take a look at the following illustration

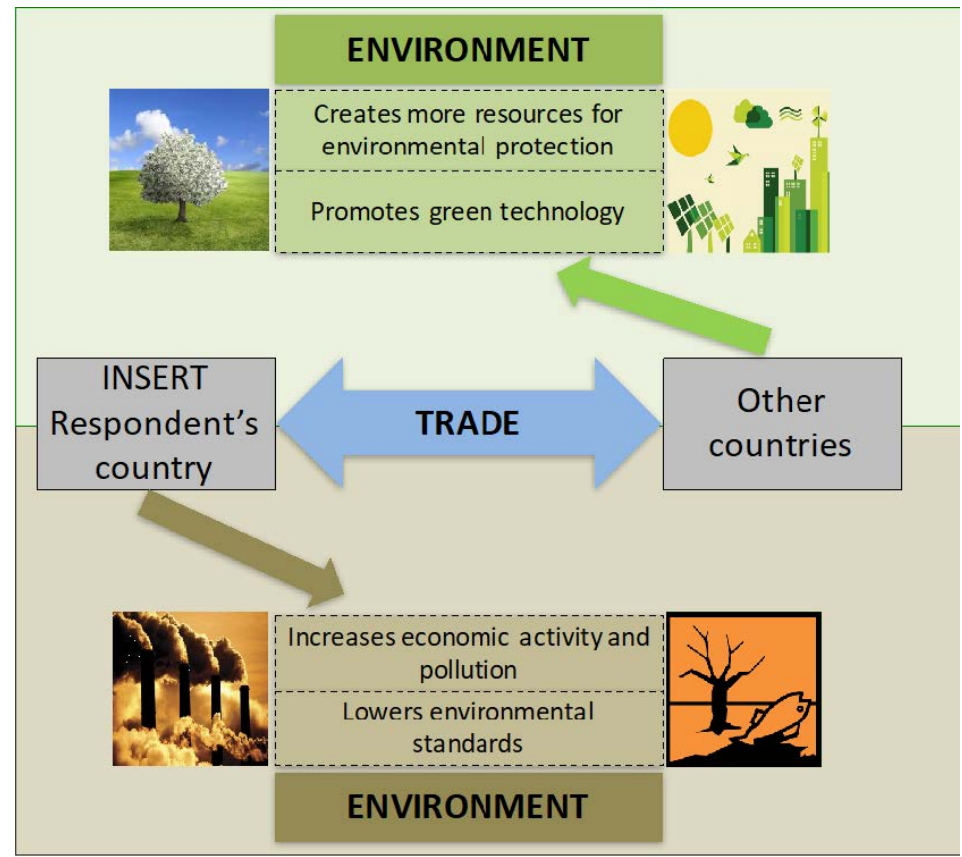

\section{- Treatment group 5:}

Please read the following information.

There has been some discussion about the relationship between international trade and protection of the environment.

There is a lot of evidence that, overall, the effects of international trade on environmental protection in Switzerland are positive, but that the effects on environmental protection in other countries with whom Switzerland trades are negative.

\section{NEW SCREEN}

On the one hand, international trade creates wealth that can be used for better environmental protection in Switzerland. International trade also promotes the development and spread of environmentally friendly technologies whose use reduces pollution and waste in Switzerland.

On the other hand, increasingly strict environmental protection standards in Switzerland have pushed highly polluting industrial production out of Switzerland and into other countries that have weaker environmental protection standards. Such goods include, for example, machines, steel, cement, paper, chemicals, food, metals, cars, or electronic devices. These goods are then exported from other countries to Switzerland. As a result, the environment in Switzerland has become cleaner while 
consumers in Switzerland are still able to buy all the goods they want. However, environmental conditions in countries with whom Switzerland trades have become worse because the environmental damage from producing many goods that people in Switzerland consume now takes place in other countries.

In brief, international trade supports environmental protection efforts and helps improve environmental conditions in Switzerland, but it does so at the expense of environmental protection efforts in other countries with whom Switzerland trades.

\section{NEW SCREEN}

Please take a look at the following illustration

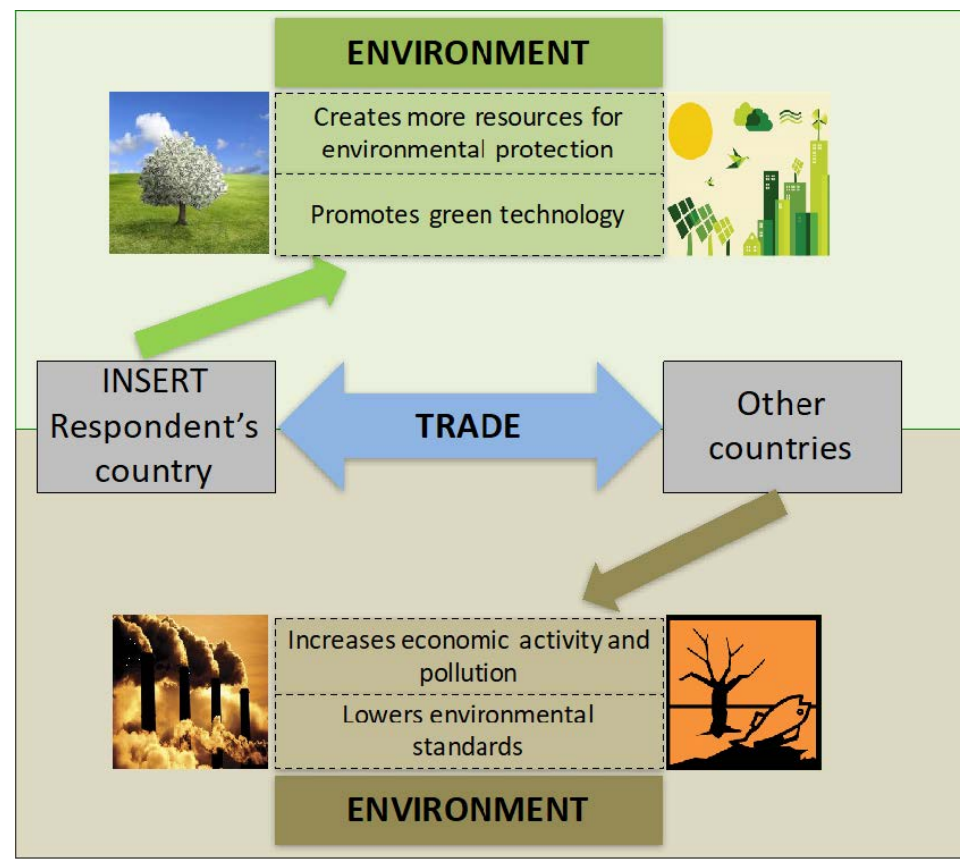

\section{A.1.2 Survey items for dependent variables in the survey-experimental study}

In the following, we list the exact wording (translated to English) of the survey items that constitute the dependent variables used in the analysis.

- Manipulation check

When you think about the effects of international trade over the next 5-10 years: in your personal view, what overall effects will international trade have on environmental protection? Please give your answer on the following scale, where 1 means "very negative" and 7 means "very positive". 
- Personal benefits

Now think about yourself and your family - what do you think about the growing trade and business ties between Switzerland and other countries. Please give your answer on the following scale, where 1 means "very bad" and 7 means "very good". These ties are ... for myself and my family.

- Country benefits

What do you think about the effects of growing trade and business ties between Switzerland and other countries on Switzerland as a whole? Please give your answer on the following scale, where 1 means "very bad" and 7 means "very good".

The ties are ... for Switzerland as a whole.

- Association tests

More generally, we would like to know the first thing that comes to your mind when you hear about international trade. Below are six word pairs displayed on a 1-7 scale with a word at each end. For each pair, please indicate which word describes your feelings better when you think about international trade. 1 means you strongly associate international trade with the word on the top; 7 means you strongly associate international trade with the word at the bottom; and if your feeling falls somewhere in between, you can choose any number in between. Please answer spontaneously; that is, think about international trade for a few seconds and then answer.

GOOD 1234567 BAD

OPPORTUNITY 1234567 THREAT

JOBS 1234567 UNEMPLOYMENT

FEAR $1234567 \mathrm{HOPE}$

POVERTY 1234567 WEALTH

FAIR 1234567 UNFAIR

- Trade policy preferences

Some people suggest that the government should limit imports of foreign goods in order to protect jobs in Switzerland. Others say that limiting imports would increase consumer prices, and hurt exports from Switzerland to other countries. Do you favor or oppose new limits on imports, or haven't you thought much about this?

1. Favor

2. Oppose

3. Have not thought much about this

4. Don't know / refuse 
- Specific policy attitudes

Please tell us how much you agree or disagree with the following statement.

1. Completely Agree

2. Mostly Agree

3. Slightly Agree

4. Slightly Disagree

5. Mostly Disagree

6. Completely Disagree

99. Don't know / refuse

\section{A.1.3 Balance tests for randomization}

We checked whether randomization worked as intended by comparing pre-treatment characteristics of survey respondents between control group and our main treatment groups 1 and 2. Appendix Table A.2 reports the results.

As some statistically significant differences seem to appear for the average distribution of age (difference by -2.7 years of age between the average control and helps treatment group respondent, and likewise +2.7 years between the average helps and hurts treatment group respondent) and education (difference in 0.12 points on the education scale between respondents in the control and hurts treatment group), we also report the distribution of the variables in the control and treatment groups 1 and 2. Appendix Figure A.1 presents the results. As it can be seen, even if the means are slightly differing, equality of the cumulative distribution function is only rejected with strong control of the family-wise error rate at a $10 \%$ level and only in the top-left panel at age ranging from 52 to 53 . We therefore conclude that randomization has worked, at least as indicated from these observable characteristics. 


\begin{tabular}{lccc}
\hline & $\begin{array}{c}\text { Control vs. } \\
\text { help }\end{array}$ & $\begin{array}{c}\text { Control vs. } \\
\text { hurt }\end{array}$ & $\begin{array}{c}\text { Help vs. } \\
\text { hurt }\end{array}$ \\
\hline \multirow{2}{*}{ Age } & $-2.750^{*}$ & -0.089 & $2.660^{*}$ \\
& $(1.153)$ & $(1.133)$ & $(1.190)$ \\
Male respondent & -0.008 & -0.007 & 0.001 \\
& $(0.044)$ & $(0.044)$ & $(0.044)$ \\
French-speaking respondent & -0.009 & 0.009 & 0.018 \\
& $(0.041)$ & $(0.041)$ & $(0.041)$ \\
Education level & 0.097 & $0.123^{*}$ & 0.026 \\
& $(0.059)$ & $(0.061)$ & $(0.059)$ \\
Respondent is employed & 0.034 & -0.027 & -0.061 \\
& $(0.042)$ & $(0.041)$ & $(0.042)$ \\
Household income & -0.292 & -0.217 & 0.076 \\
& $(0.357)$ & $(0.349)$ & $(0.359)$ \\
Household size & 0.031 & 0.081 & 0.050 \\
\hline Observations & $(0.112)$ & $(0.112)$ & $(0.116)$ \\
\hline
\end{tabular}

Table A.2: T-tests comparing the means of socio-demographic characteristics of respondents in the control group to those in the helps- and hurts-treatment groups. Standard errors in brackets. Stars denote statistically significant differences: $+(0.1), *(0.05) * *(0.01)$. 

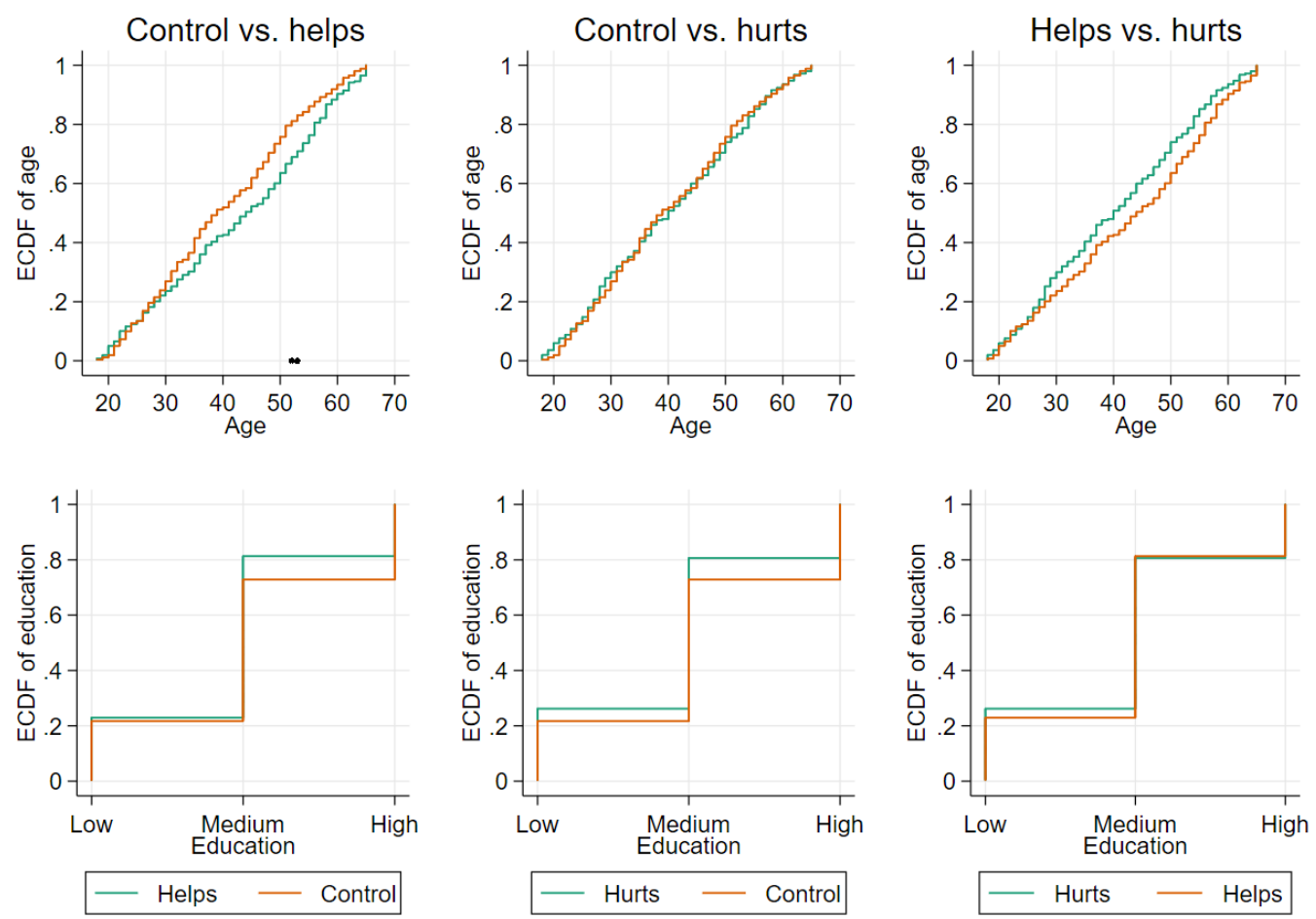

Figure A.1: Cumulative distribution of age and education variables for the control and treatment groups 1 and 2. Black dots depict ranges where cumulative distribution function equality is rejected with strong control of the familywise error rate at a $10 \%$ level.

\section{A.1.4 Manipulating domestic and foreign impacts of trade on the environ- ment}

In the following section, we present the treatment effects for the more complex treatment groups 3, 4 and 5 (see Appendix Section A.1.1). These treatments highlighted that environmental effects of trade are positive, but only for the home country (treatment 3, 'helps only home'), but only for trading partners abroad (treatment 4, 'helps only abroad'), but only for the home country due to footprint shifting (treatment 5, 'helps home extended').

We present the effects in Appendix Figures A.3 and A.2.

First of all, it is notable that with the differentiated treatments, respondents' evaluation of the overall effect of trade on the environment shifts barely (see Appendix Figures A.3 (a)), as can be expected as the overall effects are hard to discern in this case. With respect to personal and country benefits from trade (see Appendix Figures A.3 (b) and (c)), we similarly see few significant changes in the evaluation of benefits, besides the 
'extended treatment'. There, respondents in the political center evaluate such a footprintshifting policy negatively, while respondents on the political left and right see personal benefits. Also concerning implicit associations, we barely see changes in the evaluation of trade. Concerning trade policy, again few significant changes in respondents' evaluations emerge. Notable is that the 'helps only abroad' treatment reduces left respondents' preference for trade restrictions (see also Appendix Figure A.2).

Overall, we note that respondents were barely moved by the differentiated treatments. We leave it to future research to investigate why this is the case. Note that it could be fruitful to investigate whether respondents did not understand, whether the treatments did not manipulate their perception of the environmental effects of trade, or whether we indeed successfully manipulated their beliefs, but this manipulation did not bring about changes in perceived trade effects/policy preferences. We can only provide limited answers to these questions. It is noteworthy, however, that compared to the helps and hurts treatments, respondents did pass the comprehension check only slightly less frequently with the complex treatments (significantly lower only compared to the hurts-treatment with about $70 \%$ for the complex, about $75 \%$ for the helps and about $83 \%$ for the hurts treatment). With respect to manipulation, we did only ask for the respondent evaluation of the overall effects of trade - we recommend future research to assess whether respondents are moved with respect to country-level vs. foreign effects of trade on the environment by these treatments.
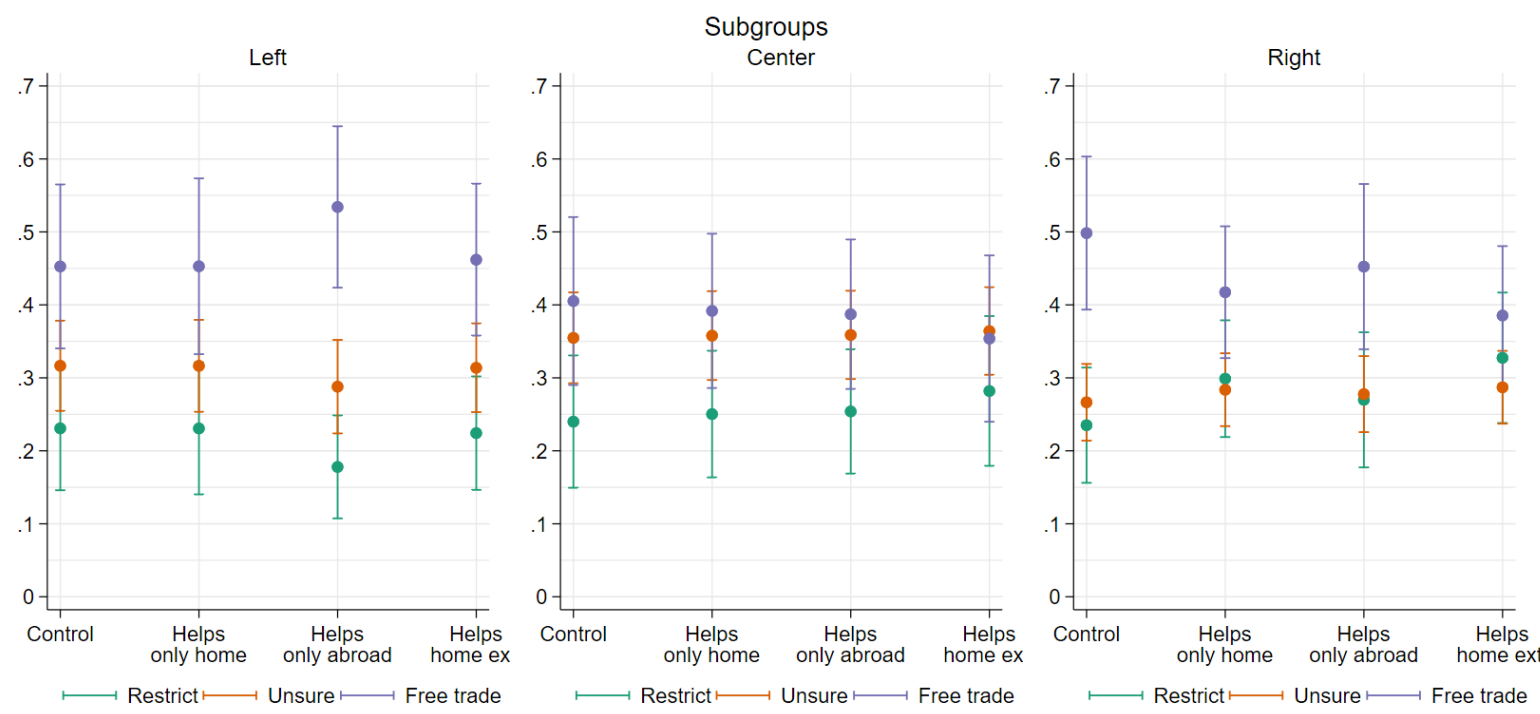

Figure A.2: Predictive margins with $95 \%$ confidence intervals after a question on favoring, don't know or opposing the introduction of import bans by treatment condition and subgroups of left-right self-placement. Margins are from coefficients from an ordered logistic regression model. 


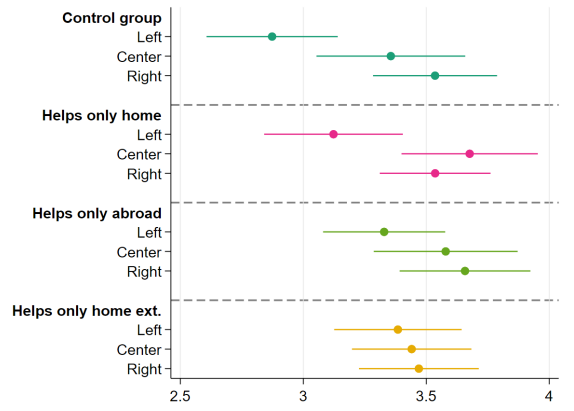

(a)

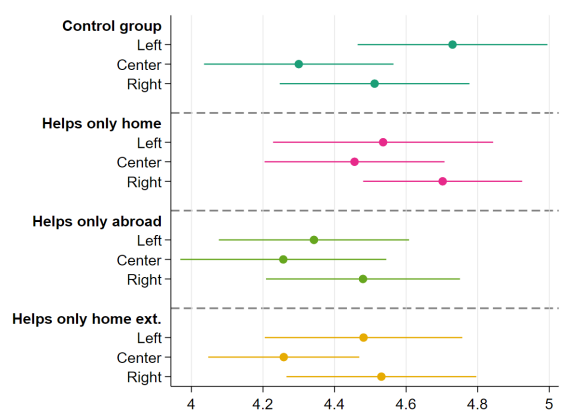

(c)

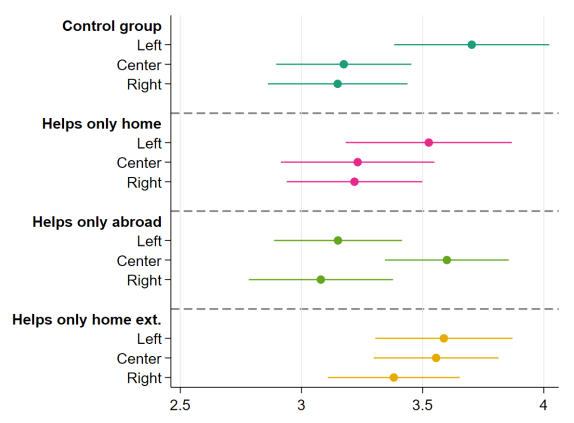

(e)

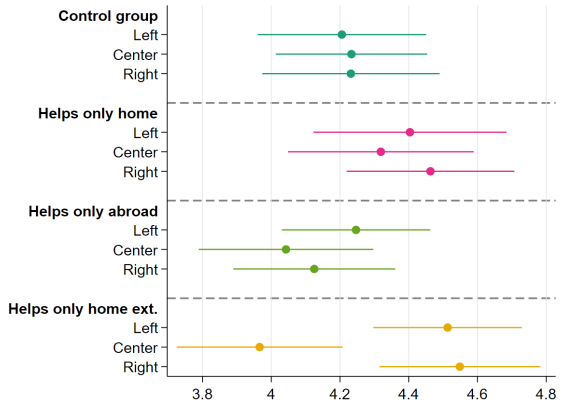

(b)

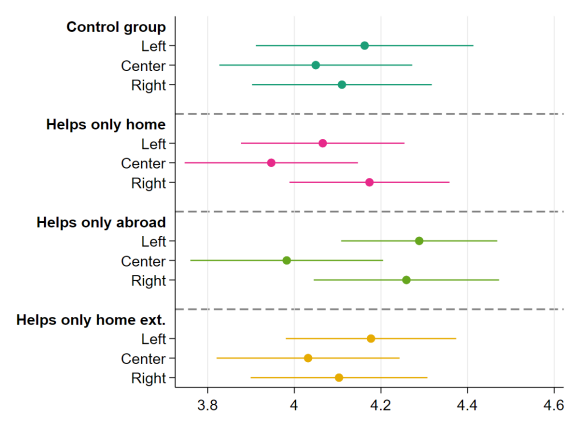

(d)

Figure A.3: a) Manipulation check: Reply to "What overall effects will international trade have on environmental protection?"

b) Reply to "What do you think about the growing trade and business ties between Switzerland and other countries?"

c) Reply to "What do you think about the growing trade and business ties between Switzerland and other countries?"

d) Index from replies to association questions ("spontanouusly", what is "the first thing that comes to your mind when you hear about international trade"?).

e) Reply to "Limit international trade to reduce negative environmental consequences?" 


\section{A.2 Supporting information for population-representative sur- vey evidence}

\section{A.2.1 Representativeness of the Survey}

The comparison of the respondent sample with the complete sample (i.e., non-respondents and respondents alike; this is a fully random and hence representative draw of the Swiss population) can be found in the public documentation (Rudolph et al. 2021). Overall, our sample performs well with respect to the distribution of gender, age, language, household size, and regional provenance of respondents. Non-Swiss citizens and people not born in Switzerland are underrepresented in our sample. The BfS sample was drawn for the resident population, not only for Swiss citizens.

Table A.3: Dependent variables

Dependent variables Description

Scale

inverted

1. Economic open- "The economic openness of Switzerland toward international ness markets brings as a whole more advantages than disadvantages for our country."

2. Economic open- "If Switzerland opens its economy to foreign countries and exness for compa- poses its companies more to international competition, Swiss nies companies will become more competitive, and that is good for our prosperity."

3. Job-related pro- "Switzerland should restrict the access of foreign products to tection the Swiss market in the sectors of the economy where jobs are in danger."

4. Agriculture pro- "Switzerland should protect its domestic agriculture more tection strongly against imports from abroad."

5. Price and qual- "For me it does not matter whether a product is made in Switzerity land or abroad as long as the quality and the price are right."

6. Safe food access "Food produced abroad that is not harmful to health should have free access to the Swiss market."

Main dimension First principal component from a Principal Component Analof trade ysis of the six items of trade presented above.

\section{A.2.2 Original items and variables specification}

The six original statements regarding trade attitudes and the main dimension of trade obtained via Principal Component Analysis are presented in Table A.3. The nine items 
used to measure the environmental concern and the resulting two explanatory variables are presented in Table A.4.

Table A.4: Environmental concern questions and variables.

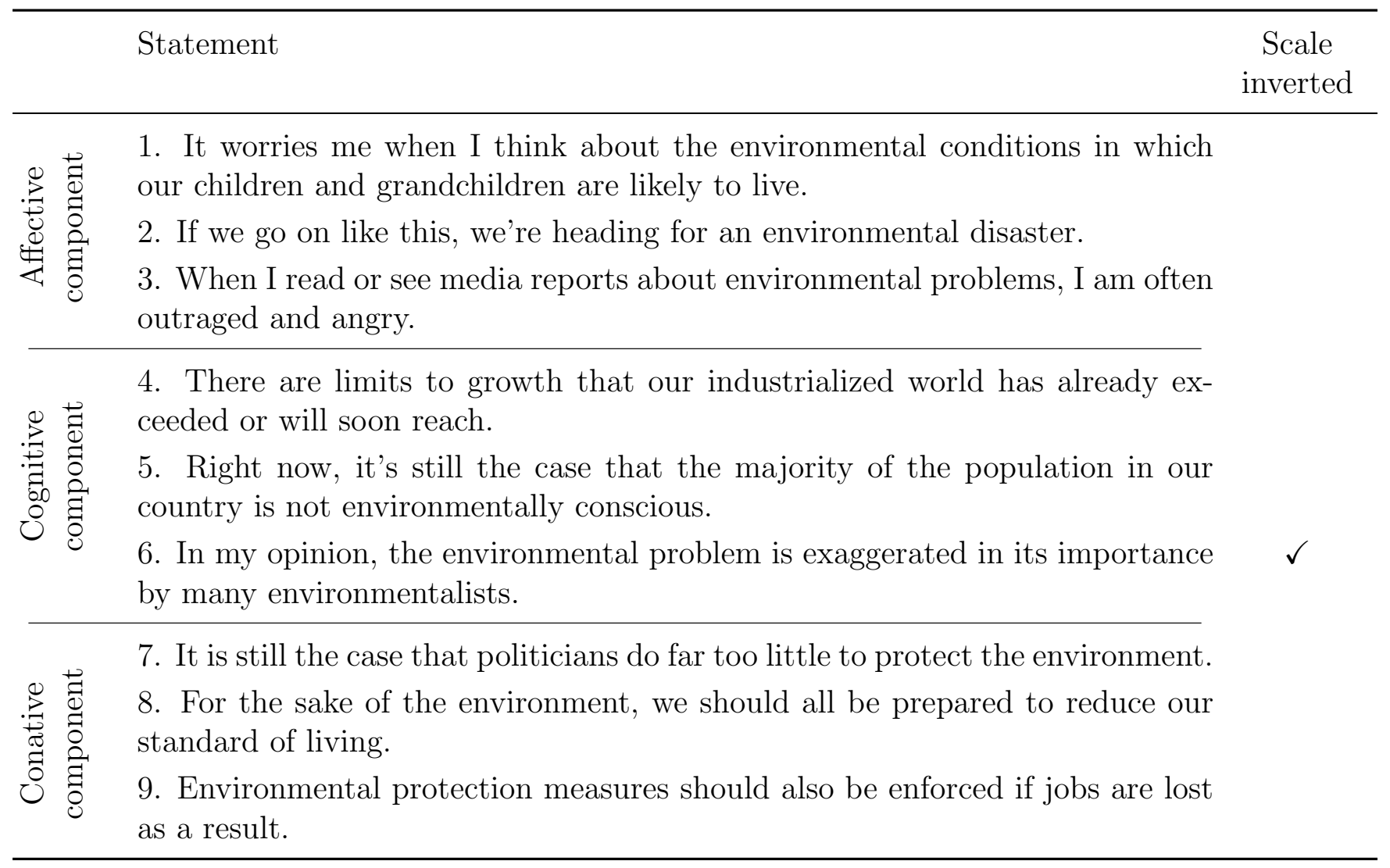

Explanatory Description

variable

Main dimension First principal component from a Principal Component Analysis of the nine of environmental items of environmental concern presented above.

concern

Environmental Mean value of the nine items of environmental concern presented above. concern

\section{A.2.3 Covariates correlation with trade preferences}

We interpret the correlation between the covariates and trade attitudes (see Appendix Table A.5). Our main dimension of trade skepticism is negatively correlated with being a student ( $5 \%$ level), the number of years of education, the income, being a foreigner and 


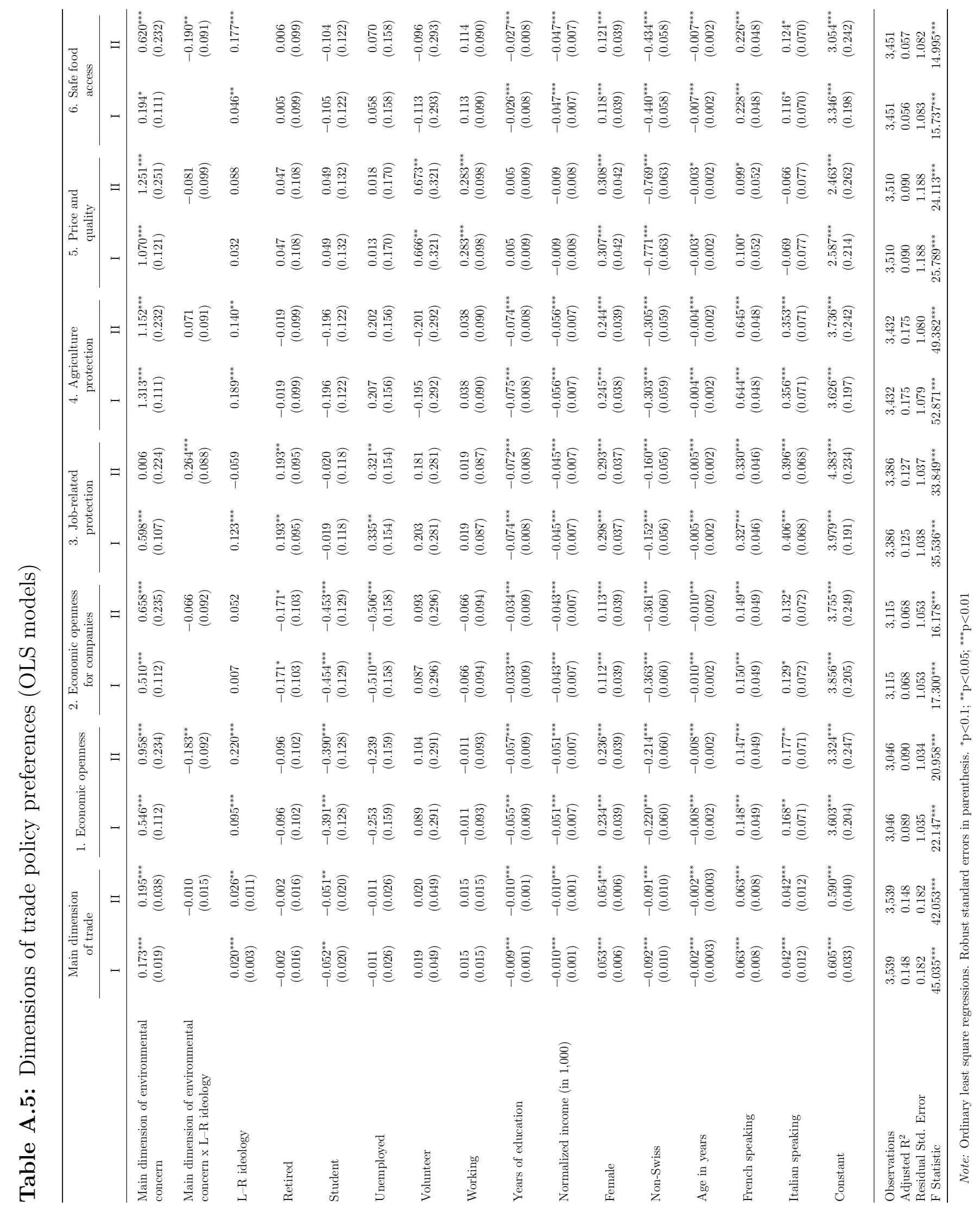


age (all at the $1 \%$ level). Trade skepticism is positively correlated with speaking French or Italian and being a Female (all at the 1\% level). As expected, individuals who could economically benefit from trade have more positive attitudes towards trade. This is in line with the embedded liberalism argument. Looking in more details at the six dimensions of trade gives a similar picture.

\section{A.2.4 Robustness check 1 - Replicating Bechtel et al. (2012)}

This section provides a replication of the empirical approach of Bechtel, Bernauer and Meyer (2012, hereafter Bechtel+; see Appendix Table A.6). Their modelization uses dichotomized dependent variables with probit models, constructs the environmental concern index additively and does not include the $\mathrm{L}-\mathrm{R}$ ideology variable in Model I.

The three dimensions of trade attitudes investigated by Bechtel+ (dependent variables one, three, five) are very similarly linked to environmental concern with respect to substantive size and significance in our sample. We also get similar results for the interaction of political ideology and environmental concern: for job-related protection, political ideology does not moderate the relationship between environmental concern and trade (same as found by Bechtel+); for price and quality the relationship is moderated (negative and significant, same as found by Bechtel+). However, we find a significant interaction term for the economic openness dimension, whereas Bechtel+ found no moderation by ideology.

The average marginal effect (AME) of environmental concern, conditional on L-R political ideology, on the six trade dimensions for this model specification (see Figure A.4) supports our general conclusions. Comparing the AMEs for the probit models to the OLS models (see Figure 2), we see that the direction of the effects, including the interactions, is captured similarly. Note that the relationship is stronger with the probit model for the dimensions economic openness for companies, and price and quality, but weaker for job-related protection. For the former, the probit (but not the OLS) models also return statistically significant interaction terms, for the latter the reverse finding holds. 

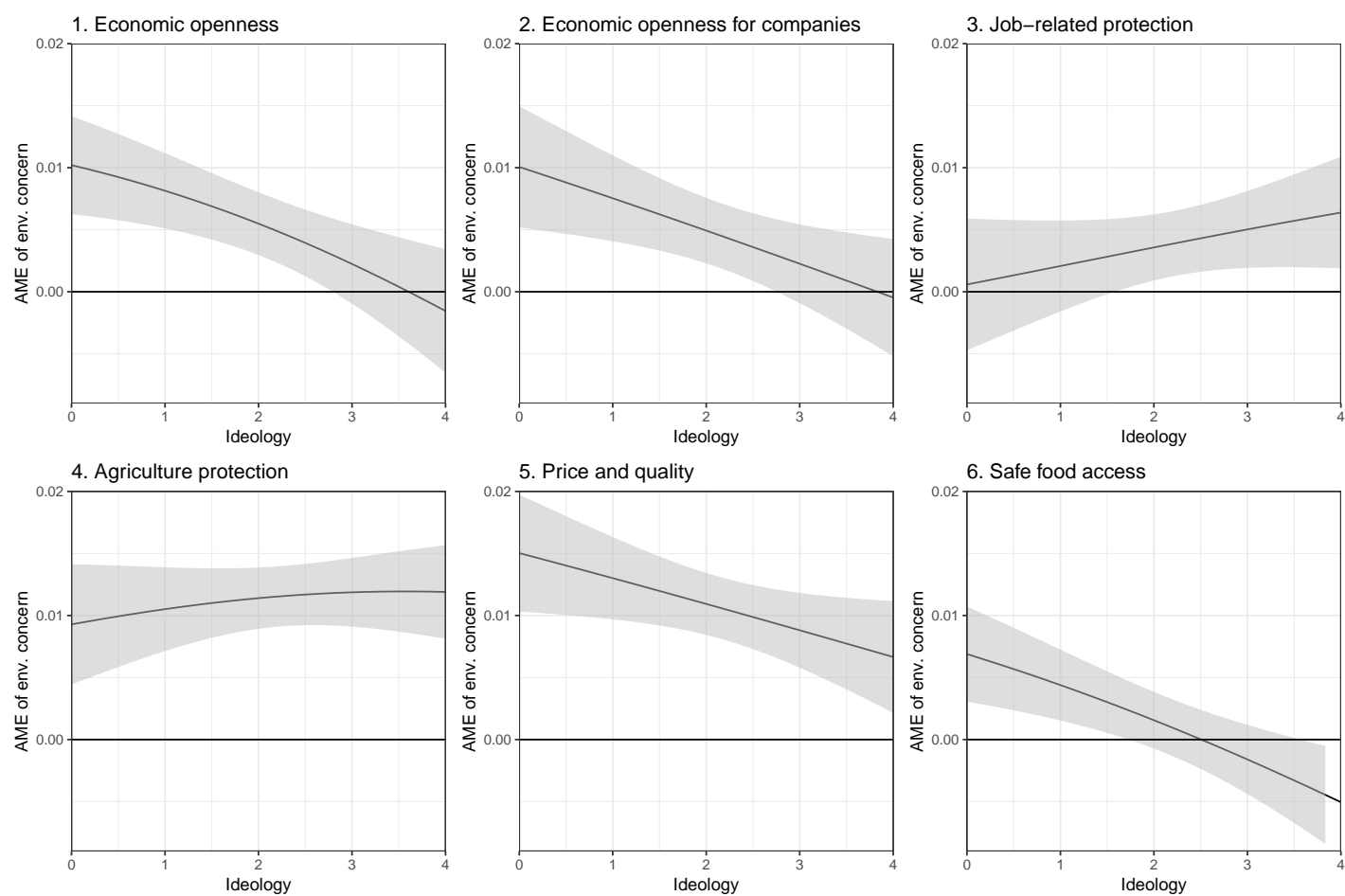

Figure A.4: Average marginal effects of environmental concerns on attitudes towards six dimensions of trade. AMEs based on probit estimates from models II with robust standard errors). 95\% confidence intervals shown. 


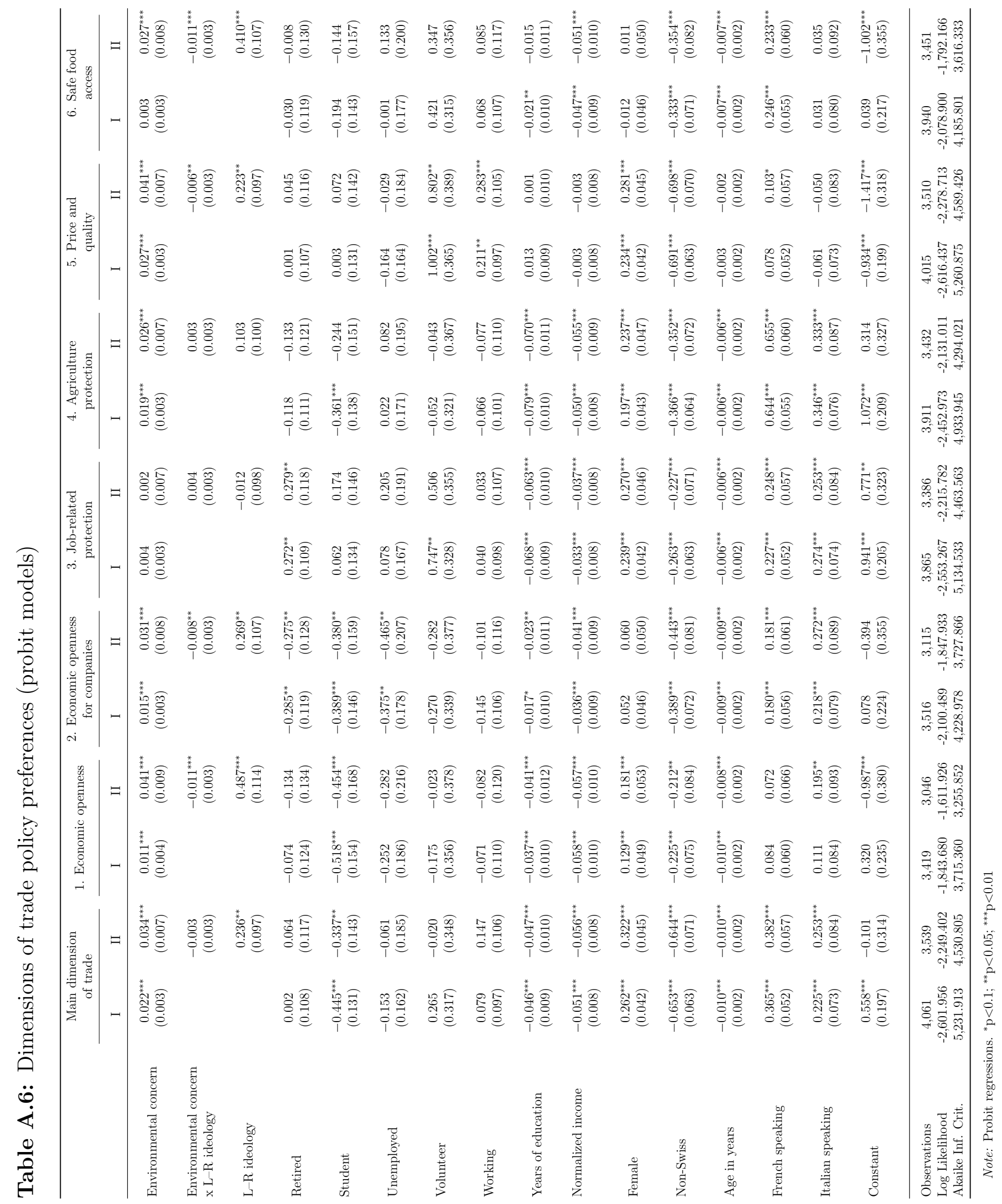




\section{A.2.5 Robustness check 2 - Linearity in interaction effects}

The models presented in Table 1 and Figure 2 are based on linear interactions between environmental concern and political ideology. Based on Hainmueller, Mummolo and Xu (2019), we provide evidence that the interaction effect between the two variables is in fact linear, and that there is no problem with the area of shared support.

First, we produce a scatter plot of the raw data that shows the six different outcome trade variables plotted against environmental concern at different levels of political ideology. As political ideology is not binary, we split it into three groups: respondents who identify as (1) left and center-left, (2) center, and (3) center-right and right. The resulting plots can be seen in Figure A.5: each row presents the scatter plot of one trade variable and environmental concern for the three levels of political ideology. First, we can see that the marginal effect is linear, as the linear slope (blue) is always very close to the LOESS fits (red). The box plots in the margins show that overall there are only slight worries of common support in the sense that we have only few respondents with very low environmental concern values, especially in the group of left-leaning respondents; but apart from that, there are plenty of respondents across the full range of the variables. 


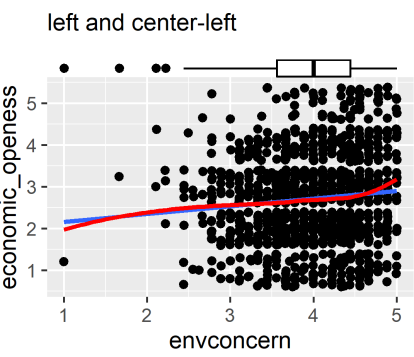

left and center-left

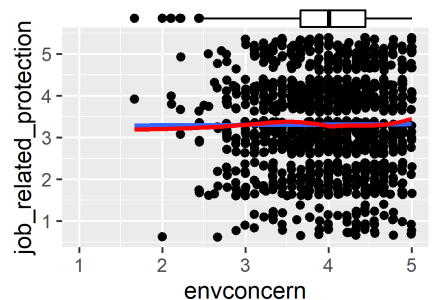

eft and center-left

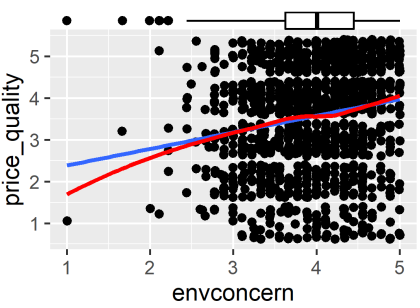

left and center-left

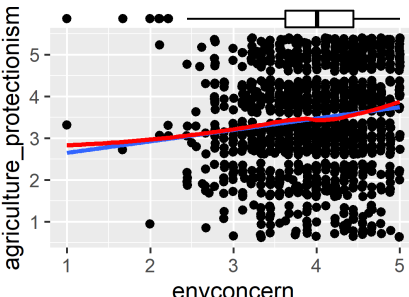

left and center-left
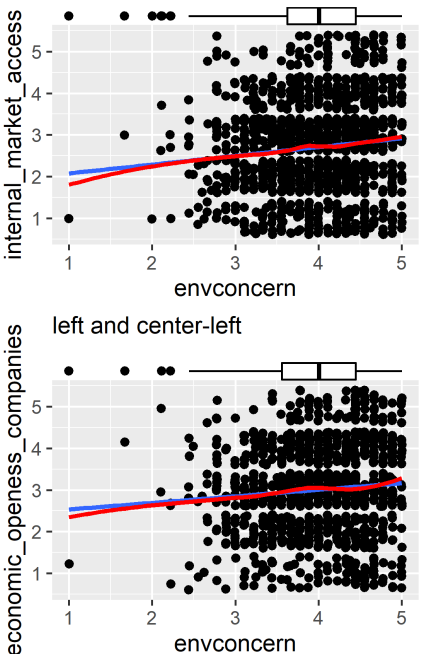

center

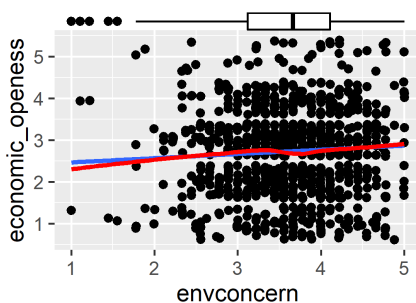

envconcern

center

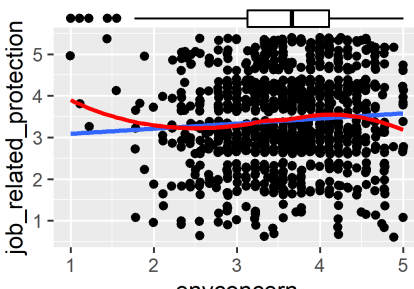

envconcern

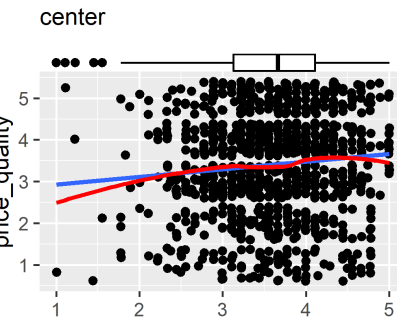

envconcern

center

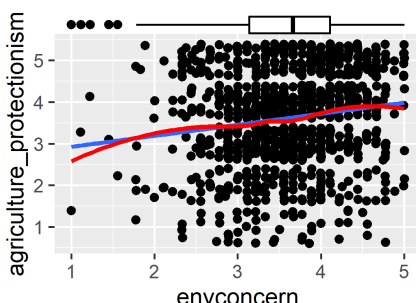

center
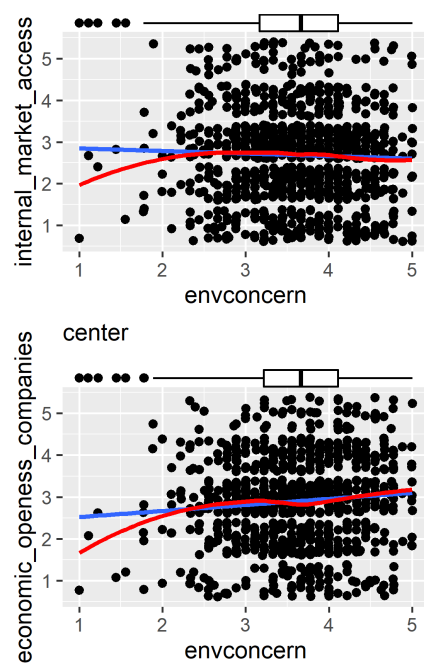

right and center-right

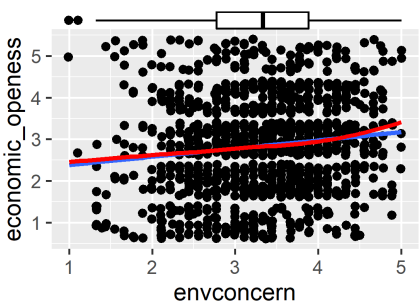

right and center-right

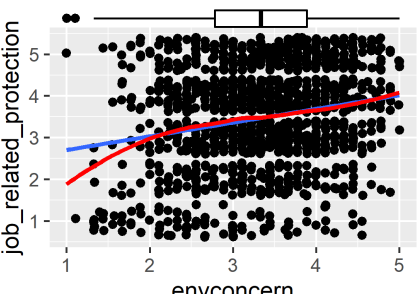

right and center-right

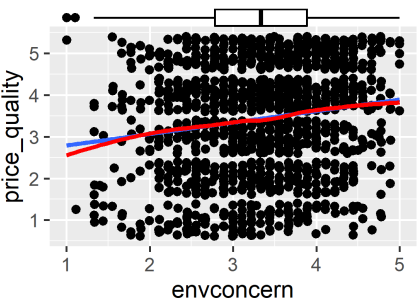

right and center-right

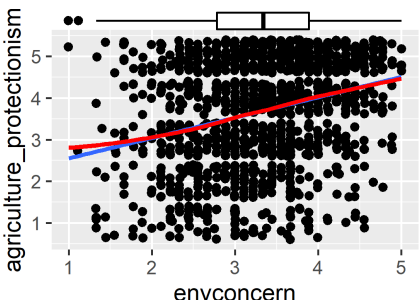

right and center-right
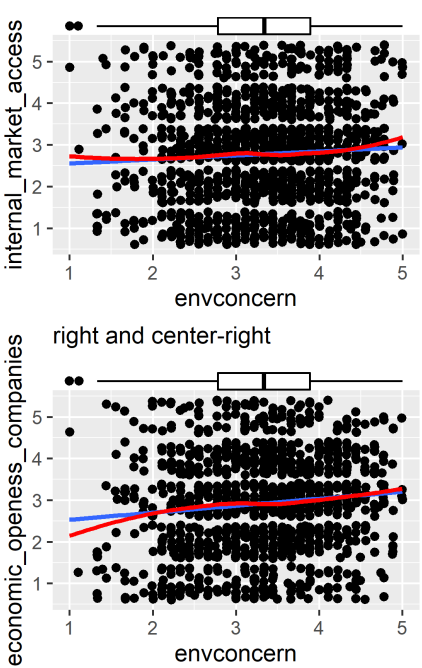

Figure A.5: Scatter plots of environment $@ b$ concern and the six trade variables at different levels of political ideology. 
In the next step, we look at the results of the binning estimator introduced in Hainmueller, Mummolo and $\mathrm{Xu}$ (2019) to see whether the conditional marginal effects of environmental concern on the trade variables are indeed linear across different levels of political ideology. Figure A.6 shows that overall, the results hold. For economic openness for companies and safe food access, the results of the linear interaction should be interpreted with caution.
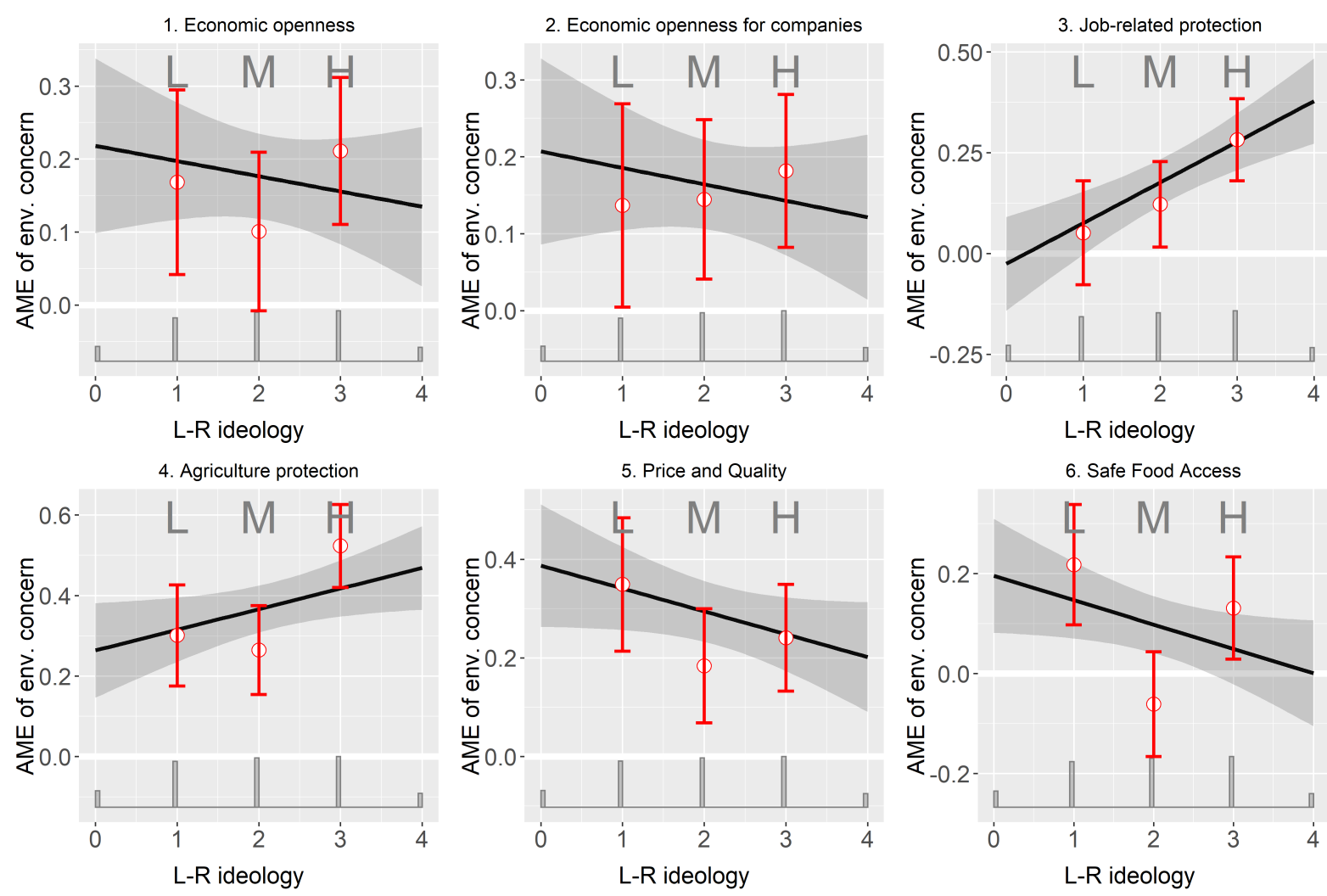

Figure A.6: Average marginal effects of environmental concern on attitudes towards six dimensions of trade, estimated using binning estimators. The shaded areas indicate the $95 \%$ confidence intervals.

\section{A.3 Reliability of the survey instrument, particularly the left- right self-placement of respondents}

Left-right self-placement is not self-evident to operationalize. For example, Bauer et al. (2017) show that citizens associations of left and right can vary substantially between individuals, complicating the construction of a reliable measure. Similarly, Jahn (2011) argues that measuring party positions over time and contexts is challenging. While these issues are relevant to our context, we propose that in using a widely used measure of 
left-right self-placement validated in other surveys, ${ }^{10}$ we capture the political ideology in a standard way in the current political science literature. Nonetheless, we discuss matters of reliability and stability (against the treatment) of this measurement below.

This is important as, for example, Fortunato, Stevenson and Vonnahme (2016) argue that citizens in Western democracies vary greatly by their political knowledge and subsequently also by how well they can order political positions along a left-right continuum, depending on how useful it is in their contexts to structure various aspects of politics along such a dimension. As Fortunato, Stevenson and Vonnahme (2016, p. 1213) point out (and besides other function described in the article), "left-right methaphors [provide for voters ...] a policy-based means of orienting themselves toward the parties". This might be relevant for our case, as left-right self-placement is a core moderator that we investigate - does an increase in factual knowledge about the environmental impacts of trade affects trade policy preferences depending on prior levels of left-right self-placement. If voters were generally unsure about how to use a left-right axis, where parties stand on the left-right axis, and ultimately where they themselves stand, their left-right position might be volatile, which raises issues of the reliability of our survey instrument, and might itself be affected by the treatment. Theoretically, the findings by Fortunato, Stevenson and Vonnahme (2016) point towards high levels of usefulness (and also knowledge) in political contexts that are guided by policymaking coalitions that orient themselves on the left-right axis. This is likely the case in Switzerland, where political poles organize mainly along one dimension (left-right and cultural-liberal fall together), with increasing polarization in recent years, and at the same time need of parties and voters to understand which parties form majorities in the Swiss Federal Council (Hänggli and Häusermann 2015). Empirically, we therefore propose that the left-right scale is useful for Swiss voters to organize politics, and that voters know what they are doing. This being said, we show below that our measure of political ideology is a reliable predictor of partisanship, that it is stable over time, that it is similarly applied in the three language regions of the country (these three findings are derived from the panel data), and lastly, that left-right self-placement it is not affected by the experimental treatments.

\section{Reliability of political ideology}

We test the reliability of respondents' self-assessed political ideology by looking at correlations with other political variables. We find that political ideology (higher values indicate more rightist respondents) has a strong negative correlation of -0.47 with naming the social democratic party (SP; left-wing) as the one which best represents one's interests and a strong positive correlation of +0.45 with naming the Swiss People's Party (SVP;

$10 \quad$ See footnote 7 in the main paper for exact wording of the question in the population-representative survey. This is similar to wording used in long-running surveys such as, e.g., the German ALLBUS (see https://www.gesis.org/allbus/inhalte-suche/frageboegen). For the survey experiment, the question wording was 'In political matters, people talk of 'the left' and 'the right'. Generally speaking, how would you place your views on this scale?," which is similar to wording used, e.g., in the long-running Swiss SELECTS study (see https ://forscenter.ch/projekte/selects/?lang=de). 


\begin{tabular}{l|l}
\hline Party & Correlation with political ideology \\
\hline SVP & +0.45 \\
\hline SP & -0.47 \\
\hline CVP & +0.06 \\
\hline FDP & +0.23 \\
\hline GPS & -0.28 \\
\hline GLP & -0.09 \\
\hline EVP & -0.02 \\
\hline PdA & -0.10 \\
\hline
\end{tabular}

Table A.7: Correlation of political ideology and party identification

right-wing; see Table A.7). When asked how important it is for a respondent that a candidate for a political office (at municipality level in one question, and at cantonal/federal level in a second question) is strongly committed to environmental protection, political ideology is highly negatively correlated with respondents' stated importance in this question. Correlation coefficients are -0.38 when asked about a candidate on the municipality level, and -0.40 for the cantonal/federal level.

\section{Stability of political ideology over time}

We test the stability of respondents' political ideology by comparing the measures used in this paper with a later wave of the panel study which was fielded one and a half years later (with an eleven-point scale). As Figure A.7 shows, the correlation between the two measures is very strong $(\mathrm{p}=0.81)$ which we interpret as a sign of a very stable measurement of political ideology.

\section{Difference between language regions}

For the variables of trade attitudes (first dimension of the PCA) and environmental concern, there are only very minor differences between the language regions within Switzerland. As Figure A.8 shows, both the distributions and the median values are very similar for the three language regions; in one case, the median is actually identical. We thus argue that these attitudes do not vary across language regions, giving another indication for stability of this indicator of ideology between language regions, and making it also less problematic that the survey experiment was not fielded in Italian.

\section{Effects of treatment on left-right self placement}

Last, we show that our survey experimental treatments do not affect the left-right selfplacement of respondents (we can do this, as left-right self-placement was asked towards the end of the survey, after the treatment and the questions on trade policy preferences). As we propose left-right self-placement as a core moderator of how environmental concern affects trade policy attitudes, this is important to rule out, as otherwise endogeneity would 


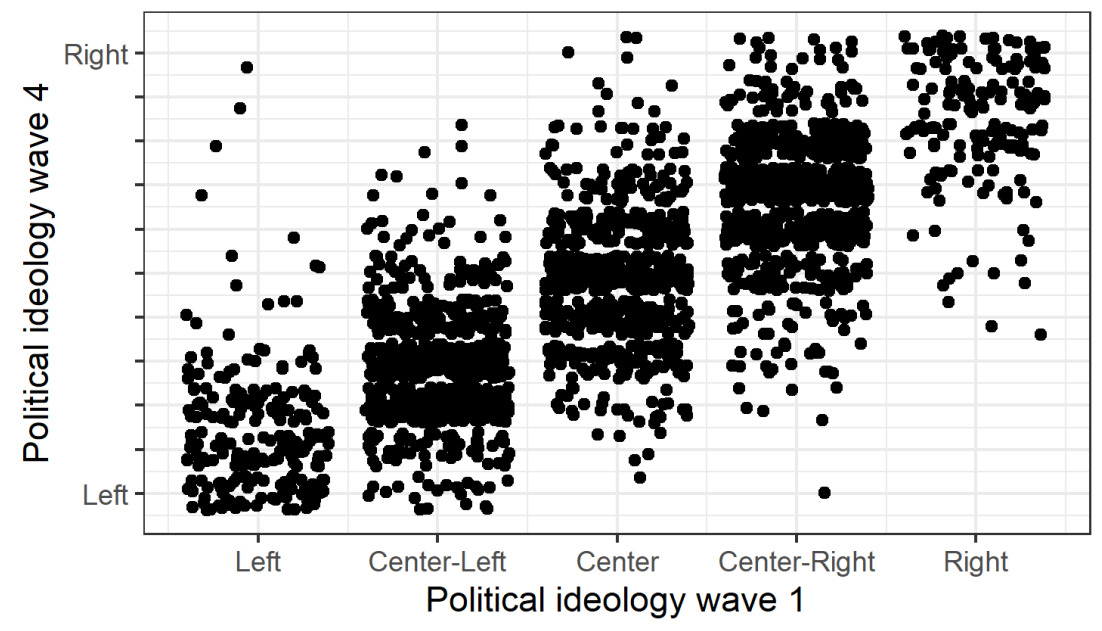

Figure A.7: Stability of political ideology over time. Scatter plot of respondents leftright self-placement in the first wave (2018, 5-point scale) versus in the fourth wave $(2019 / 20,11$-point scale) of the panel.
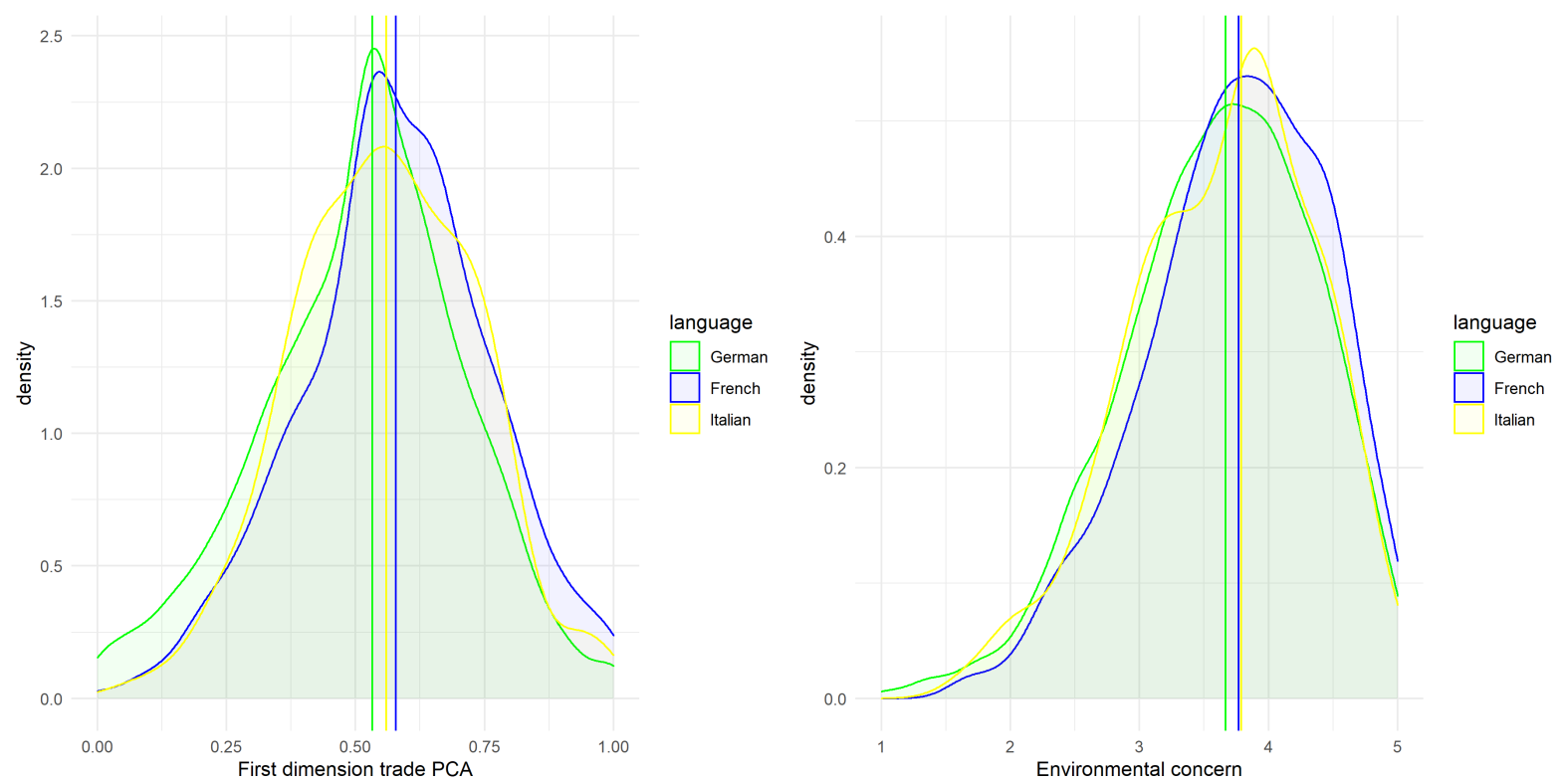

Figure A.8: Distribution of trade attitudes and environmental concern in different language regions. Vertical lines mark the median value. Note that the median of environmental concern is identical for French and Italian respondents; noise was added to show both vertical lines.

bias subgroup treatment effects by ideology. As reported in Appendix Table A.8, this does not seem to be a concern. We see no relevant association between the treatments and left-right placement (be it continuously operationalized on a scale from 1 to 7 , or with a 
binary indicator of "left", "centrist" or "right" placement.) The slight association between the "Helps only home" treatment condition and the left-right axis, significant at the $10 \%$ level in some models, disappears once we include socio-demographic control variables - this points to the reason being rather some imbalance in respondent characteristics between treatment groups, and not an influence of the treatment itself. 


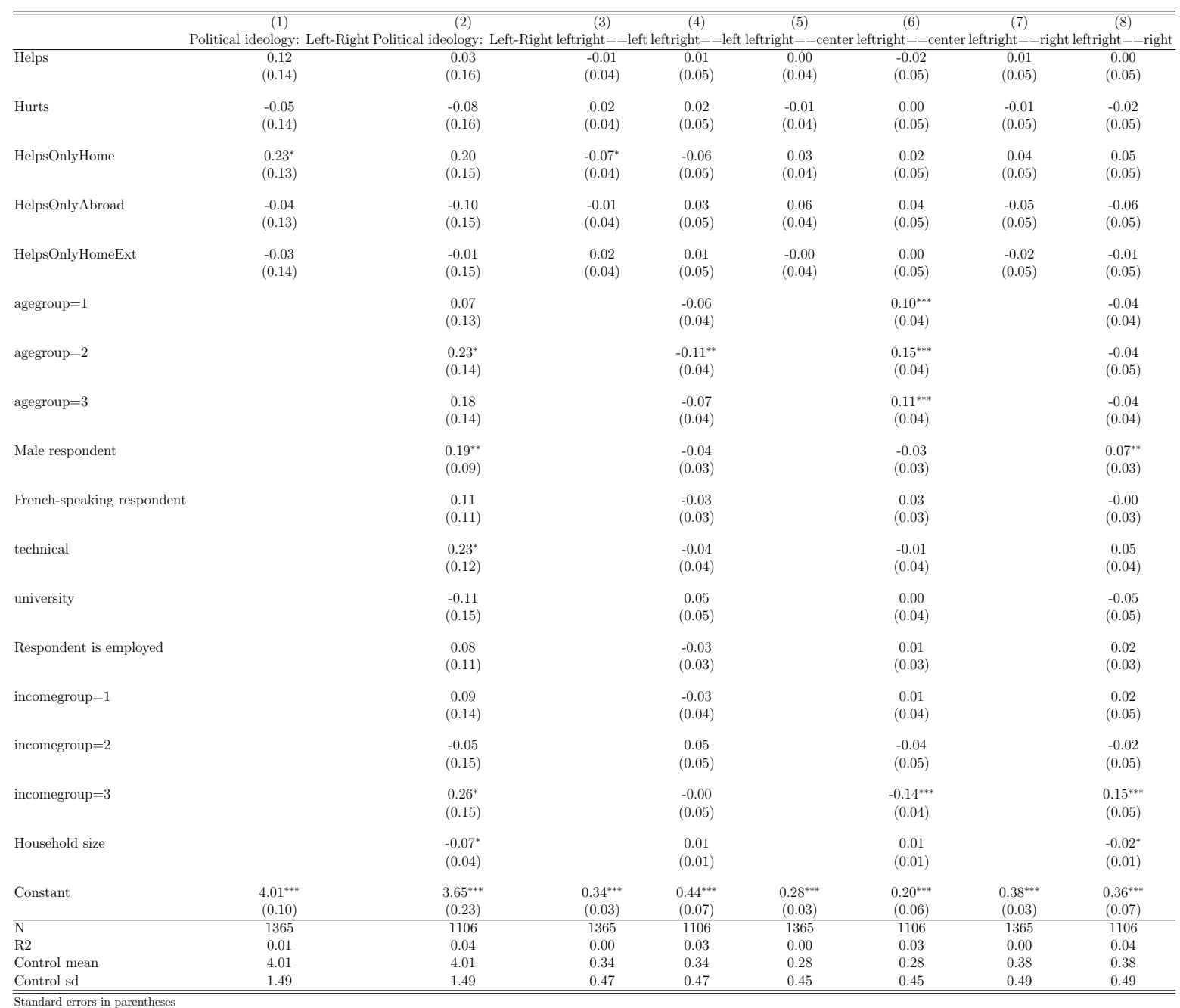

Table A.8: Regression of respondents left-right self-placement (scale 1-7) on treatment conditions in models 1 and 2. Regression of respondent having a left-leaning ideology (model 3 and 4), a centrist ideology (model 5 and 6) or a rightleaning ideology (model 7 and 8) on treatment conditions. Models 2, 4, 6, 8 include additional control variables. Robust standard errors in brackets. 


\section{A.4 Case context and external validity}

\section{A.4.1 Case}

This subsection provides additional background on the relevance of trade policy for the Swiss economy and for Swiss politics.

We start by assessing how contested environmental and trade policy are between and within the main political parties of Switzerland, and how salient the issue is for voters. Appendix Figure A.9 presents the average scores of party candidates for the 2019 national election on the environmental and trade policy dimensions. As can be seen, parties differ widely on both dimensions, and all policy positions are hence represented in parliament and offered to voters (note that the third quadrant, low environmental protection and high trade barriers, has no political party representing it on average). On top of the variation between party means, we see substantial within-party variation. Crosses, which represent the range of positions of $70 \%$ of parties' candidates (hence, each cross is excluding the $30 \%$ deviating most from their parties' means), indicate that with few exceptions (Green party) parties are very heterogeneous on trade and environmental policy. Given the open list system of Switzerland, voters can opt for candidates reflecting their particular tradeenvironment preferences in all quadrants but the third.

Next, we assess the salience of trade and environmental policy for Swiss voters. For this, we draw on a most important issue question part of the first (2018) and fourth wave (2020) of the (see Rudolph et al. 2021) . There, 36\% of respondents indicate that "Environment/Climate Change", and 9.1\% of respondents indicate that "Globalization/Free trade" is among the 3 most important political issues for Switzerland. ${ }^{11}$ In the fourth wave of the panel, $50.1 \%$ of respondents indicate that "Environment/Climate Change", and still $9.1 \%$ of respondents indicate that "Globalization/Free trade" is among the 3 most important political issues for Switzerland.

We conclude that trade and environmental policy meaningfully differentiate political parties and candidates in Switzerland, and that a substantial share of voters sees both environment and trade policy as a highly relevant policy field, adding real-world relevance to the question we pose in this article.

\section{A.4.2 Environmental concern and trade policy preferences in comparison with other high-income countries}

Next, to shed more light on the potential contexts to which our results could generalize, we compare Swiss trade exposure and Swiss citizens' environmental concern levels and trade policy preferences to those of citizens in other OECD countries.

Concerning the level of envirnmental concern, and as illustrated in Figure A.10, Swiss citizens hold a similar level of concern as citizens in other high-income countries. The

11 For comparison, the top-4 named problems are "retirement funds/pensions" (53.0\%), health care system/health insurance" (51.6\%), "environment/climate change" (36\%), and "refugees/asylum seekers" $(26.7 \%)$. 


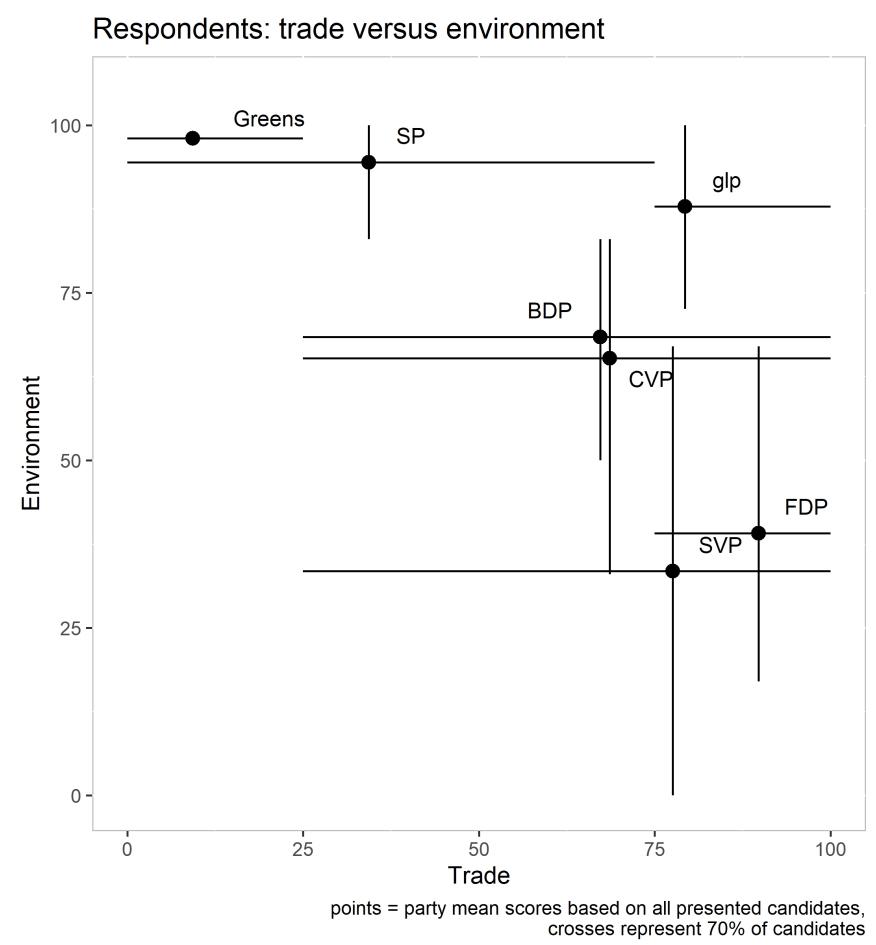

Figure A.9: Policy positions of political candidates in the 2019 national election by party and policy issue (item wording for trade policy: "Should Switzerland strive for a free trade agreement with the USA?"; item wording for environmental policy: "Stronger environmental protection is necessary, even if its application limits economic growth"). Data from the Smartvote voting advice application, which asks policy questions to every candidate before elections and makes this information publicly available to Swiss voters. $83 \%$ of political candidates participated in the Smartvote survey.

comparison is based on data from the Environment III survey (2010) of the International Social Survey Programme ISSP Research Group (2019). Answer to the question "Generally speaking, how concerned are you about environmental issues?" on a 5-points Likert scale $(1=$ Not at all concerned, $5=$ Very concerned) is displayed (one dimensional index). Answers to three items, "We worry too much about the future of the environment and not enough about prices and jobs today", "Almost everything we do in modern life harms the environment" and "People worry too much about human progress harming the environment" on a 5 -points Likert scale $(1=$ Agree strongly, $5=$ Disagree strongly $)$ are aggregated into a single index and displayed (aggregate index). 


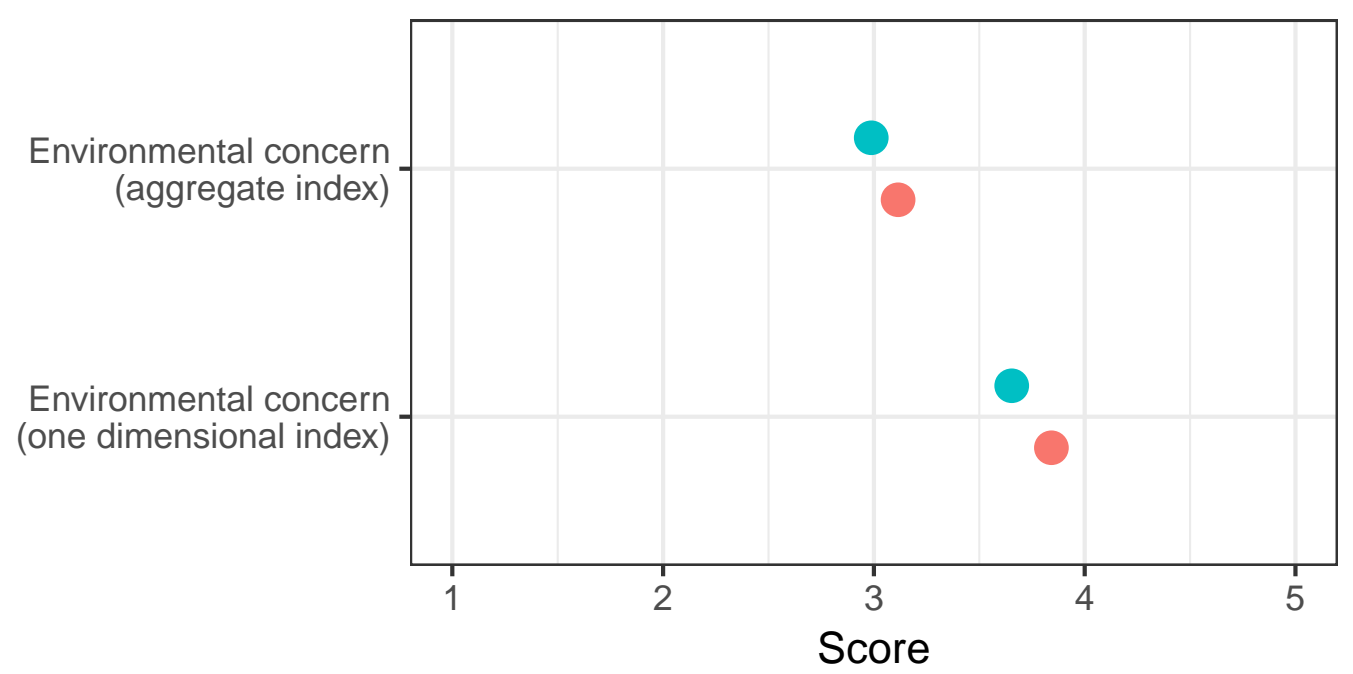

Switzerland High-income countries

Figure A.10: Mean score on environmental concern indicators of Swiss citizens (red, N top to bottom $=1208,1204$ ) and citizens of other high-income countries, (blue, $\mathrm{N}$ top to bottom $=15899,15794$ ). Whiskers denote $95 \%$ confidence intervals. High-income countries: Australia, Belgium, Denmark, Finland, France, Germany, Iceland, New Zealand, Norway, Sweden, United Kingdom, United States.

Swiss citizens hold a similar level of perception of perceived personal trade impact, slightly higher trade knowledge and similar preferences to limit international trade compared to citizens in other high-income countries. The comparison is based on data from a quota-representative survey by the company IPSOS in the US, Canada, Australia, France, Germany and by Nguyen, Huber and Bernauer (2021) in Switzerland . ${ }^{12}$ We display the answers to questions on (i) trade impact in Appendix Figure A.11 ("In your opinion, how much of an impact do decisions concerning international trade, taken by the government in [insert capital of respondent's country], have on your personal economic situation?", with a 5 -points Likert scale; $1=$ No impact, $5=$ Very big impact; for the full sample as pre-treatment question), (ii) trade knowledge in Appendix Figure A.12 ("In your opinion, how much do you personally know about international trade issues between [insert respondent's country] and other countries in the world?", on a 4-point scale; 1=Nothing or almost nothing, $4=\mathrm{A}$ lot; for the full sample as pre-treatment question), and (iii) trade policy preferences in Appendix Figure A.13 ("Do you favor or oppose new limits

12 The Swiss part of this survey constitutes the data used for the survey experimental part of this article. We use pre-treatment or control group comparisons here to learn on how Swiss citizens views differ from those of other countries, on average. 
on imports, or haven't you thought much about this?", with answer categories $1=$ Favor, $2=$ Oppose, $3=$ Have not thought much about this and $4=$ Don't know / refuse, which we recode to a binary measure favor vs. rest, and for which we use the control group samples only as this question was displayed post-treatment).

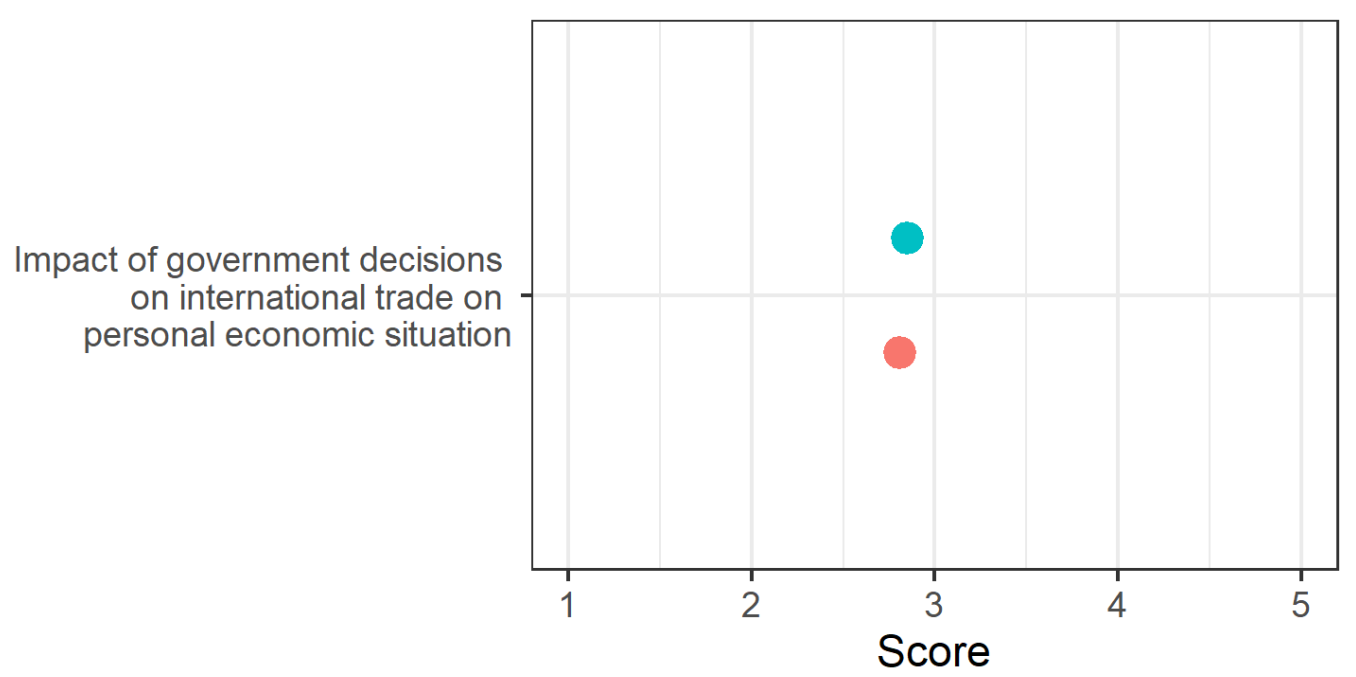

Pooled Countries

Switzerland

Figure A.11: Mean score on perceived personal trade impact (scale 1-5) of Swiss citizens (red, $\mathrm{N}$ top to bottom $=1538$ ) and citizens of other high-income countries, (blue, $\mathrm{N}$ top to bottom $=7514$ ). Whiskers denote $95 \%$ confidence intervals. High-income countries: US, Canada, Australia, France, Germany. 


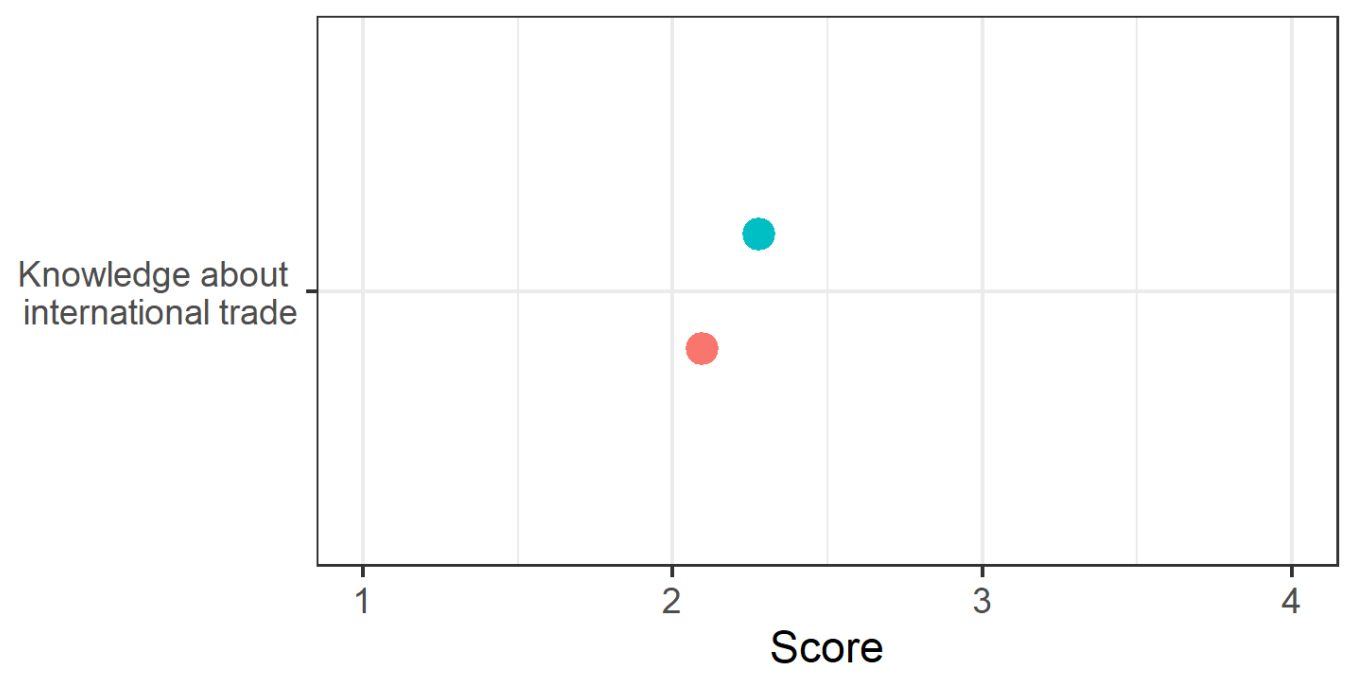

Pooled Countries Switzerland

Figure A.12: Mean score on perceived trade knowledge (scale 1-4) of Swiss citizens (red, $\mathrm{N}$ top to bottom $=1538$ ) and citizens of other high-income countries, (blue, $\mathrm{N}$ top to bottom $=7514$ ). Whiskers denote $95 \%$ confidence intervals. High-income countries: US, Canada, Australia, France, Germany. 


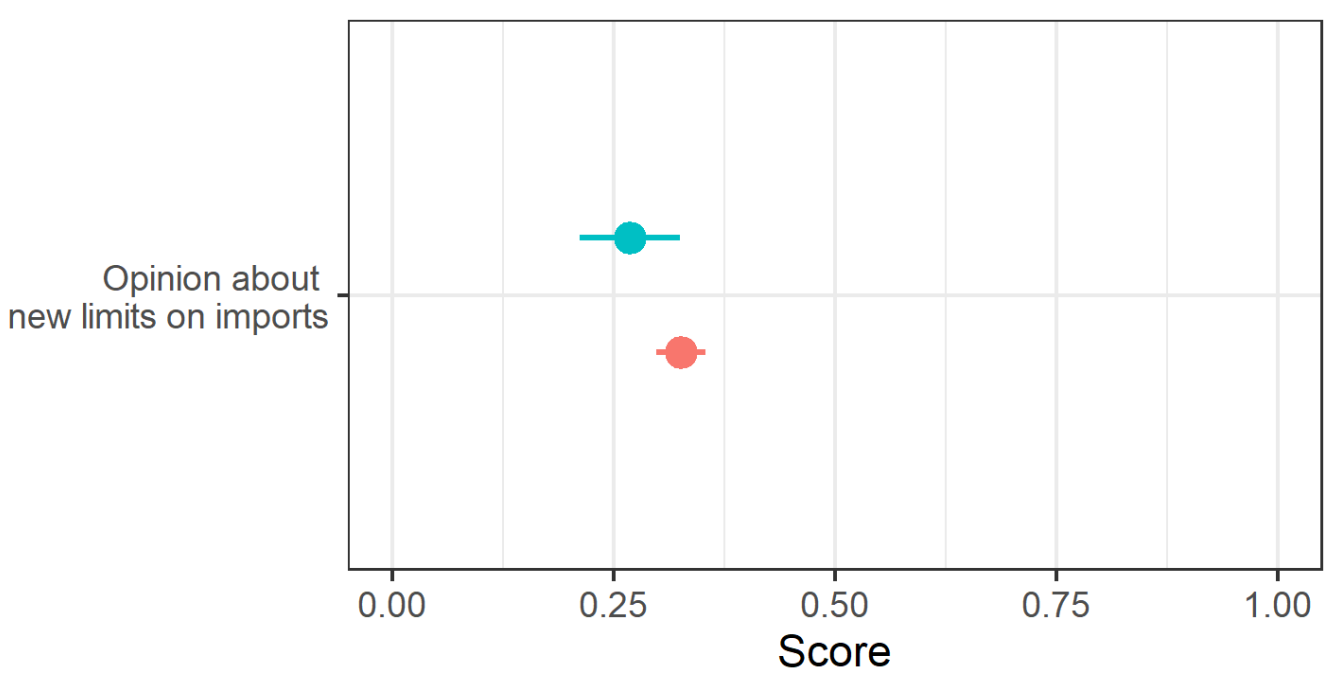

Pooled Countries

Switzerland

Figure A.13: Mean score on trade policy (scale 0-1 with 1 = favor new limits on imports) of Swiss citizens (red, $\mathrm{N}$ top to bottom $=239$ ) and citizens of other high-income countries, (blue, $\mathrm{N}$ top to bottom $=1129$ ). Whiskers denote 95\% confidence intervals. High-income countries: US, Canada, Australia, France, Germany

\section{A.4.3 Relevance of trade for GDP in Switzerland and other OECD countries}

Lastly, we show that trade is vital for the Swiss economy. Based on data from World Bank (2020, Trade as \% of GDP, see Appendix Figure A.14) and Gygli et al. (2019, KOF Overall Economic Globalization Index, see Appendix Figure A.15), we show that in the last 20 years, Switzerland has had a very high trade volume compared to other OECD countries, amounting to around $120 \%$ of GDP in the 2010s, and scores very high on an index of economic globalization compared to other OECD countries. 


\section{Trade as \% of GDP}

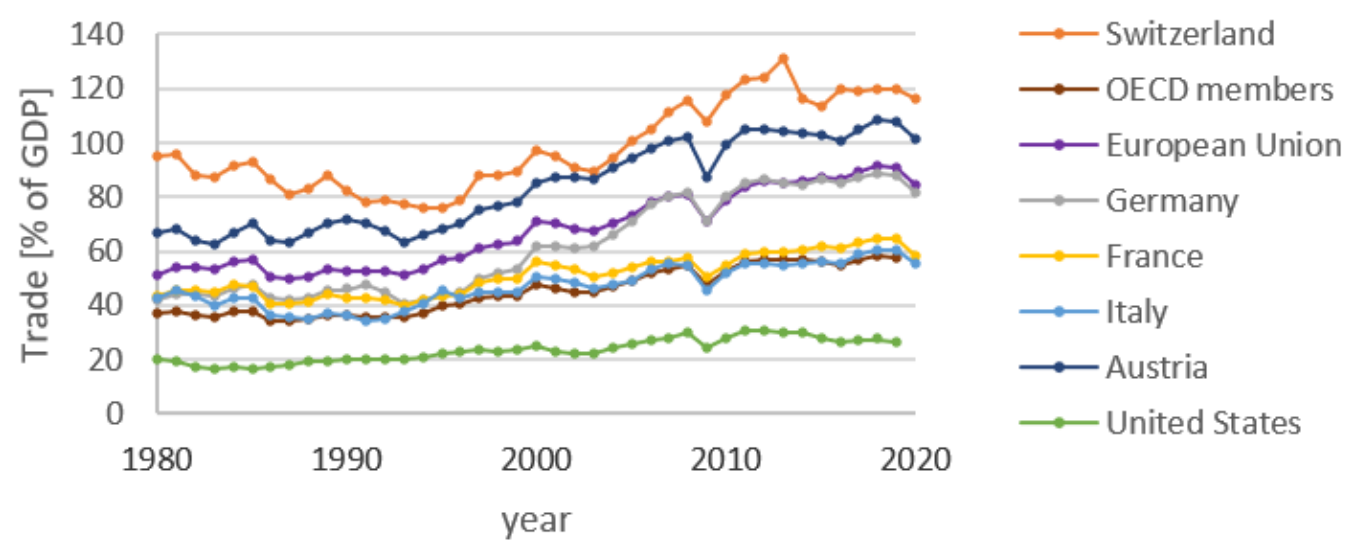

Figure A.14: Trade as a percentage of gross domestic product (GDP) for various countries between 1980 and 2020, based on data from World Bank (2020). Trade is defined as the sum of imports and exports of goods and services.

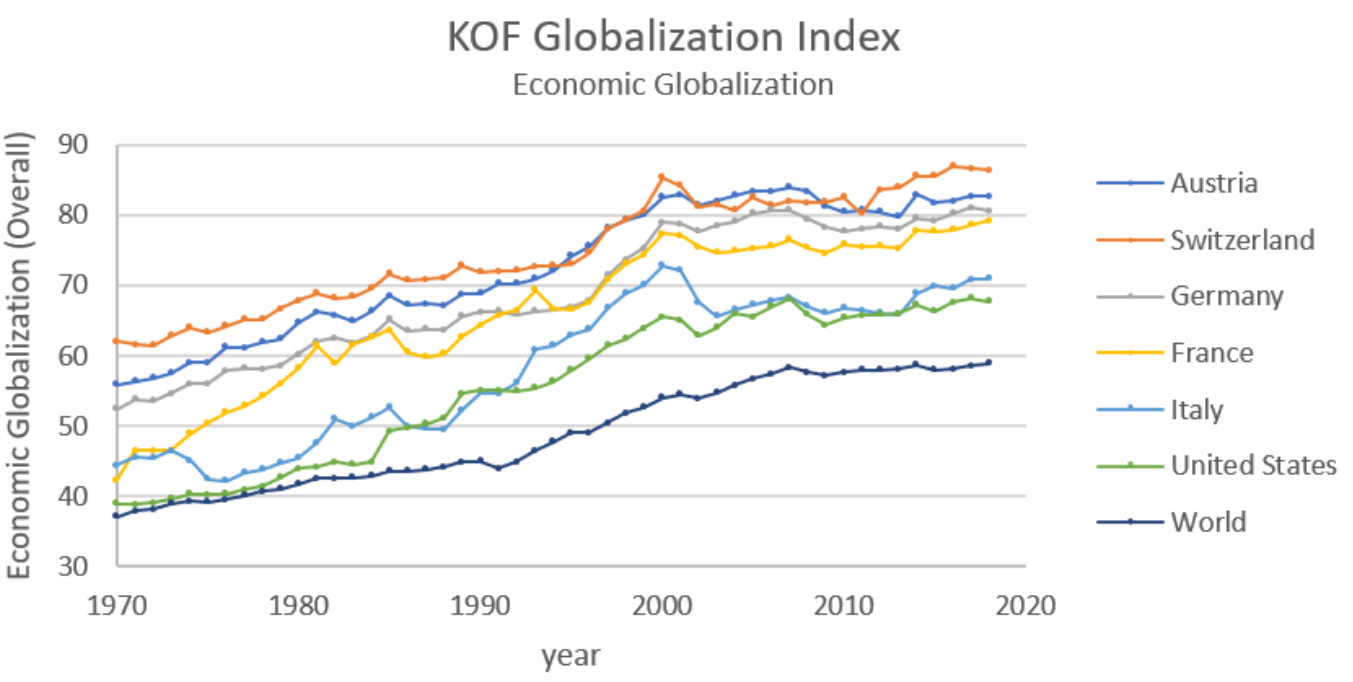

Figure A.15: Based on data from Gygli et al. (2019), the chart shows economic globalization, a subcategory of the KOF Index, for various countries between 1970 and 2018, taking into account all measured cross-border flows and activities as well as activities and policies that favor them in theory. The KOF Globalization Index measures the political, social and economic dimensions of globalization. 


\section{A References}

Bauer, Paul C, Pablo Barberá, Kathrin Ackermann and Aaron Venetz. 2017. "Is the left-right scale a valid measure of ideology?" Political Behavior 39(3):553-583.

Bechtel, Michael M., Thomas Bernauer and Reto Meyer. 2012. "The green side of protectionism: Environmental concerns and three facets of trade policy preferences." Review of International Political Economy 19(5):837-866.

Fortunato, David, Randolph T Stevenson and Greg Vonnahme. 2016. "Context and political knowledge: Explaining cross-national variation in partisan left-right knowledge." The Journal of Politics 78(4):1211-1228.

Gygli, Savina, Florian Haelg, Niklas Potrafke and Jan-Egbert Sturm. 2019. "The KOF Globalisation Index - revisited." The Review of International Organizations 14(3):543574.

Hainmueller, Jens, Jonathan Mummolo and Yiqing Xu. 2019. "How much should we trust estimates from multiplicative interaction models? Simple tools to improve empirical practice." Political Analysis 27(2):163-192.

Hänggli, Regula and Silja Häusermann. 2015. "Consensus lost? Disenchanted democracy in Switzerland." Swiss Political Science Review 21(4):475-490.

ISSP Research Group. 2019. "International Social Survey Programme: Environment III - ISSP 2010." GESIS Datenarchiv, Köln. ZA5500 Datenfile Version 3.0.0, https://doi.org/10.4232/1.13271.

Jahn, Detlef. 2011. "Conceptualizing Left and Right in comparative politics: Towards a deductive approach." Party Politics 17(6):745-765.

Nguyen, Quynh, Robert A Huber and Thomas Bernauer. 2021. "Environmental Impacts and Public Opinion About International Trade: Experimental Evidence from Six OECD Countries." Global Environmental Politics pp. 1-28.

Rudolph, Lukas, Franziska Quoß, Sarah Gomm, Stefan Wehrli and Thomas Bernauer. 2021. "Environmental Panel Study 2018-2019, Wave 1-3, Cumulative Data.". Version Number: 1.0.0 type: dataset.

World Bank. 2020. "The World Bank Data - Trade (\% of GDP).".

URL: https://data.worldbank.org/indicator/NE.TRD.GNFS.ZS 